\title{
Techno-economic modeling and optimization of solar-driven high-temperature electrolysis systems
}

\author{
Meng Lin, Sophia Haussener* \\ Laboratory of Renewable Energy Science and Engineering, EPFL, Station 9, 1015 Lausanne, Switzerland
}

\section{A R T I C L E I N F O}

\section{Article history:}

Received 9 January 2017

Received in revised form 24 July 2017

Accepted 26 July 2017

Available online 9 August 2017

\section{Keywords:}

Concentrated solar

Photovoltaics

High-temperature electrolysis

Techno-economical analysis

\begin{abstract}
A B S T R A C T
We present a techno-economic analysis of solar-driven high-temperature electrolysis systems used for the production of hydrogen and synthesis gas. We consider different strategies for the incorporation of solar energy, distinguished by the use of differing technologies to provide solar power and heat: $(i)$ thermal approaches (system 1) using concentrated solar technologies to provide heat and to generate electricity through thermodynamic cycles, (ii) electrical approaches (system 2) using photovoltaic technologies to provide electricity and to generate heat through electrical heaters, and (iii) hybrid approaches (system 3) utilizing concentrated solar technologies and photovoltaics to provide heat and electricity, respectively. We find that system 3 generates hydrogen at a high efficiency $\left(\eta_{\mathrm{STF}}=9.9 \%\right.$, slightly lower than the best performing system 1 with $10.6 \%)$ and at a low cost $\left(C_{\mathrm{fuel}}=\$ 4.9 / \mathrm{kg}\right.$, lowest cost of all three systems) at reference conditions, providing evidence for the competitiveness of this hybrid approach for scaled solar hydrogen generation. Sensitivity analysis indicates an optimal working temperature for system 3 of $1350 \mathrm{~K}$, which balances the increased thermal receiver losses with the reduced electrolysis cell potential when increasing the temperature. Lower working pressure always favors high system efficiency and low cost. The working current densities for thermoneutral voltage were determined for various temperature and pressure combinations, and trends for efficient and cost-effective thermoneutral operation were identified. The water conversion extent was optimized to avoid mass transport limitations in the electrodes while ensuring large fuel generation rates. For synthesis gas production, a $\mathrm{H}_{2} / \mathrm{CO}$ molar ratio of 2 can be achieved by tuning the inlet feeding molar ratio of $\mathrm{CO}_{2} /$ $\mathrm{H}_{2} \mathrm{O}$, temperature, and pressure. This study introduces a flexible simulation framework of solar-driven high-temperature electrolysis systems allowing for the assessment of competing solar integration approaches and for the guidance of the operational conditions maximizing efficiency and minimizing cost, providing pathways for scalable solar fuel processing.
\end{abstract}

(c) 2017 Elsevier Ltd. All rights reserved.

\section{Introduction}

A high-temperature electrolysis (HTE) system requires heat and electricity as input, both ideally supplied by sustainable and renewable energy sources such as solar, wind, or biomass (Balat, 2009; Shi et al., 2015). HTE of water and $\mathrm{CO}_{2}$ driven by renewable energies can potentially lead to the sustainable large-scale production of hydrogen and synthesis gas (a mixture of $\mathrm{H}_{2}$ and $\mathrm{CO}$ ). Synthesis gas can then be processed into liquid fuels through a FischerTropsch synthesis, providing a direct pathway for the renewable production of liquid fuels. Compared to ambient temperature electrolysis, HTE has the advantage of operating at reduced electrical potentials and, consequently, enhanced efficiency. This potential

\footnotetext{
* Corresponding author.

E-mail address: sophia.haussener@epfl.ch (S. Haussener).
}

reduction results from elevated temperatures which reduce the equilibrium potential, reaction overpotential, and ohmic losses in the solid electrolyte (Graves et al., 2011).

The coupling of HTE with solar energy provides a promising route for large-scale solar fuel generation. Solar energy is a versatile source and can be incorporated in HTE systems as a supplier of electricity through concentrated solar power (CSP) or photovoltaics (PV), in addition to being a supplier of high-temperature heat through concentrated solar heat. HTE driven by concentrated solar technologies is interesting because high-temperature steam and $\mathrm{CO}_{2}$ can be supplied to simultaneously produce both electrical power (by a conventional power cycle), and high temperature reactants (direct heating by the solar receiver) for the electrolysis process (Houaijia et al., 2015; Padin, 2000). Design guidelines for optimized concentrated solar-driven HTE systems have been proposed based on a system process model (AlZahrani and Dincer, 


\section{Nomenclature}

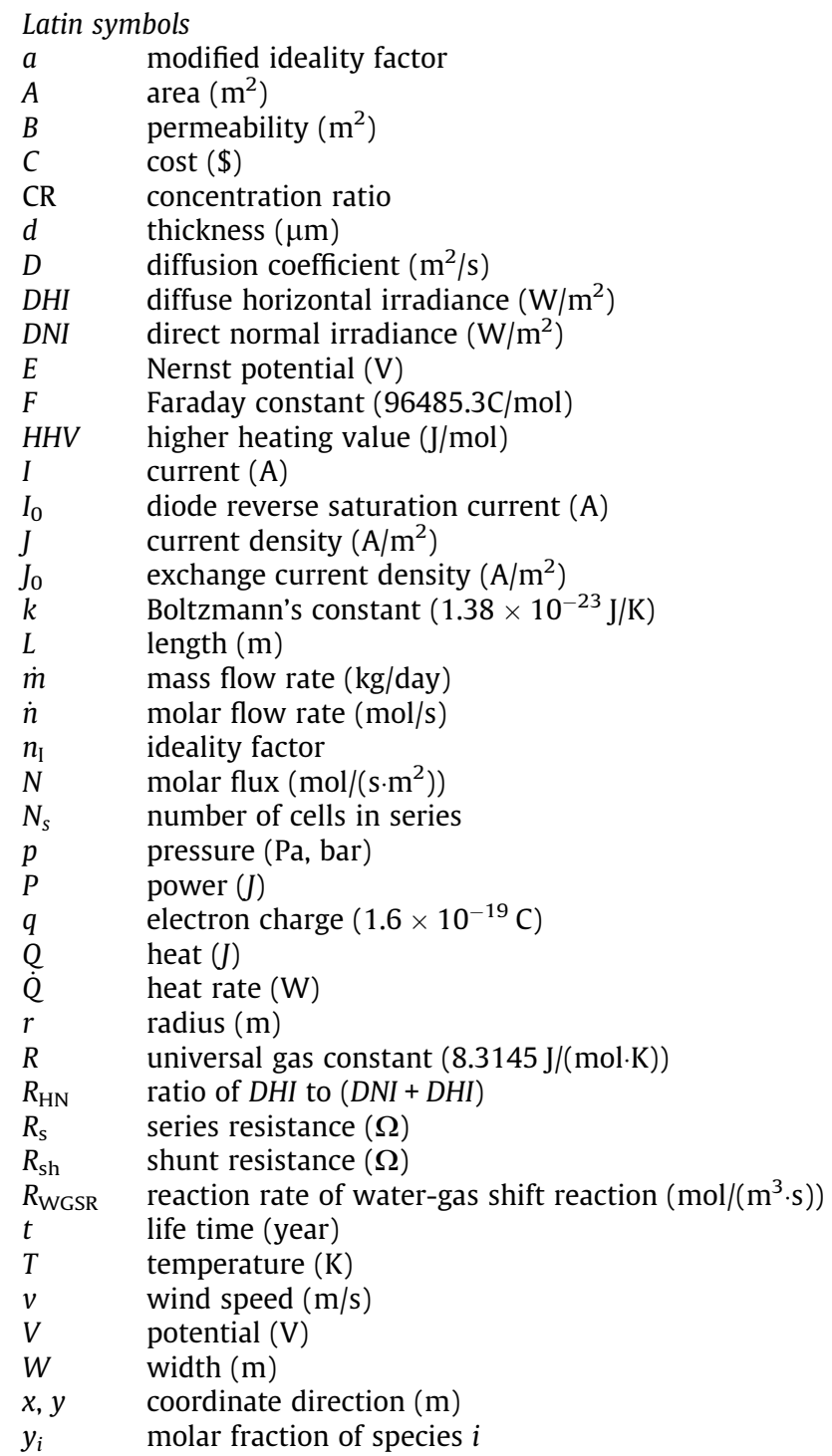

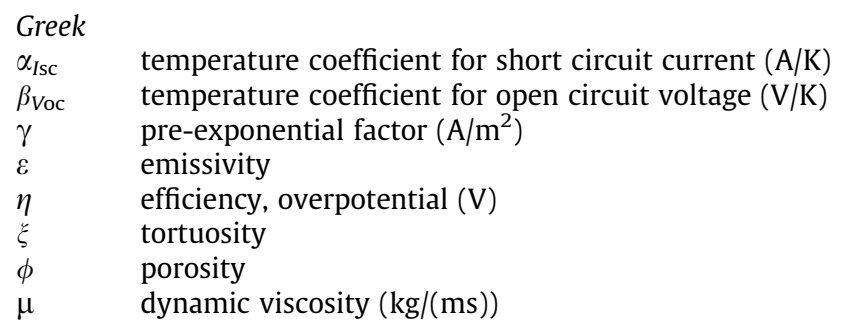

\section{Subscripts}

0 reference condition

a anode

act activation

ap aperture

av average

c cathode

ce conversion extent

conv convection

CSP concentrated solar power

CEI channel-electrode interface

d direct

e electrolyte

eff effective value

el electrolyzer

gc gas channel

HE heat exchanger

$i, j \quad$ species index

ind indirect

invest investment

$k \quad$ Knudsen diffusion

L light

mp maximum power

noct nominal cell temperature value

oc open circuit

PV photovoltaics

rad radiation

re receiver

sc short circuit

tn thermoneutral

TPB triple-phase boundary
2016; Sanz-Bermejo et al., 2014b). These systems suffer from a high hydrogen production price because of the high capital cost of solar concentrating systems (Holladay et al., 2009). Technoeconomic models of HTE systems coupled with concentrated solar technologies using various coupling strategies are required to provide performance and cost estimates as well as to provide guidance for the design and optimization of cost-competitive systems. PV power generation is less costly and simpler (due to the absence of a solar tower and power block) than CSP generation. The introduction of PV into HTE systems shows the potential to reduce fuel production costs. Commercial polycrystalline Si-based PV shows solar-to-electricity efficiencies above $15 \%$, and advanced PV technologies (multi-junction, III-V materials) can attain up to $42 \%$ (Sağol et al., 2007). A techno-economic analysis has shown that a hybrid HTE system (using parabolic trough concentrators for reactant heating and monocrystalline PV panels for electricity), with an optimized heat recovery system, leads to cheaper hydrogen production costs compared to a concentrated solar technology driven HTE system (Koumi Ngoh et al., 2014). This analysis used an outlet steam temperature for the parabolic trough concentrator of $593 \mathrm{~K}$, and further heating to the operation temperature by the electrolyzer exhaust was needed requiring exothermic operation of the electrolyzer, increasing electricity demand. No details on tradeoffs between the benefits of electrolyzer performance and enhanced reradiation losses in the solar receiver at higher operating temperature were given. More sophisticated HTE system analysis is required in order to quantify the performance and cost response of the system to varying operating conditions and to alternative solar coupling approaches.

HTE systems can be used for the production of synthesis gas which can be further processed by a Fischer-Tropsch process to generate liquid fuels (Becker et al., 2012). The advantages of co-electrolysis of $\mathrm{H}_{2} \mathrm{O}$ and $\mathrm{CO}_{2}$ over separate electrolysis lie in: (i) alleviating the problem of carbon deposition during dry $\mathrm{CO}_{2}$ electrolysis, and (ii) omitting the use of an additional water-gas shift reactor, since $\mathrm{H}_{2}$ thermochemically converts $\mathrm{CO}_{2}$ into $\mathrm{CO}$ in the electrolyzer (Stoots et al., 2009). Detailed numerical models have been proposed to predict the performance of high-temperature 
co-electrolysis, considering mass transport, electrochemical reaction, and the reversible water-gas shift reaction (Aicart et al., 2016, 2015; Menon et al., 2015; Ni, 2012a, 2012b). However, a more detailed elaboration on the impact of the working conditions (cathode inlet gas composition, operating temperature, and pressure) on the product gas composition is needed in order to ensure a HTE system design that robustly produces a well-controlled product composition.

Here we present the development of a techno-economic model applied to different solar-driven HTE hydrogen or synthesis gas processing systems, distinguished by their approaches for solar integration: pure thermal, pure electrical, and hybrid approaches. Pure thermal approaches (system 1) use solar heat to heat the reactants and to drive a thermodynamic power cycle, whose electricity powers the electrolyzer stack and other system auxiliaries, such as pumps and compressors. Pure electrical approaches (system 2) use solar-electricity (PV electricity) to drive HTE and other system auxiliaries, and to drive resistive heaters for fulfilling the heating needs of the system (reactant heating). Hybrid approaches (system 3) use concentrated solar technologies to provide heat for heating needs and PV electricity to fulfill electrical needs. For each system approach, we develop a comprehensive performance model based on: a detailed quasi 2-dimensional electrolyzer model, an equivalent circuit PV model, lumped parameter models of the solar receiver and auxiliary components, and a thermodynamic power cycle model. For each system, the complete performance model is coupled to an economic model accounting for the direct capital investment, indirect cost (including engineering, procurement, commissioning, and management), contingency cost, and operation and maintenance costs. The complete model allows for a direct comparison of the three approaches using performance criteria (e.g. solar-to-fuel efficiency) and economic criteria (e.g. levelized fuel price) under various design and operational conditions, and using various material and device choices. The results provide guidance for the implementation of a scalable demonstrator system.

\section{System description}

We use two relatively mature technologies for the design of our systems: (i) concentrated solar technologies, and (ii) photovoltaic technologies. Based on these technologies, we sketched three solar-driven HTE systems, illustrated in Fig. 1. System 1 is based on solar thermal input only, system 2 is based on solar electricity input only, and system 3 is based on a hybrid of solar heat and solar electricity inputs. In system 1 , concentrated solar radiation is the source which heats and superheats the reactants, as well as heats a heat transfer fluid to drive a thermodynamic cycle for electricity generation. We consider two independent receivers, differentiated by the working pressure: receiver 1 for the reactant heating (steam generation, and steam and $\mathrm{CO}_{2}$ (super-) heating) works at low pressure (1-25 atm), and receiver 2 for pressurized steam generation works at a high pressure (50-70 atm). Receiver 1 feeds the electrolyzer, while receiver 2 feeds a Rankine cycle with two-stage regeneration. The feed water for receiver 1 is combined with recycled water from the cathode exhaust and pumped into mixer 1 , where it is mixed with feed $\mathrm{CO}_{2} / \mathrm{H}_{2} / \mathrm{CO}$ gases and recycled $\mathrm{CO}_{2}$ from compressor 2 . The mixture $\left(\mathrm{H}_{2}, \mathrm{CO}, \mathrm{H}_{2} \mathrm{O}\right.$, and $\left.\mathrm{CO}_{2}\right)$ is preheated in heat exchanger 1 using the recovered heat from the cathode exhaust before it enters receiver 1 , where it is heated to $5 \mathrm{~K}$ below the targeted operating temperature of the electrolyzer, $T_{\mathrm{el}}$. The electrical heater 1 is used to adjust and stabilize the fluid temperature to $T_{\mathrm{el}}$. The reactant mixture is fed to the electrolyzer's cathode, where steam $/ \mathrm{CO}_{2}$ is split into $\mathrm{H}_{2} / \mathrm{CO}$ with conversion extent, $W_{\text {ce. }}$ The high temperature exhaust (a mixture of $\mathrm{H}_{2}, \mathrm{CO}$, $\mathrm{H}_{2} \mathrm{O}$, and $\mathrm{CO}_{2}$ ) is recovered in heat exchanger 1 , condensed in the condenser (splitting liquid water from the gases), and separated into pure $\mathrm{CO}_{2}$ (piped into mixer 2 for recycling) and $\mathrm{H}_{2} / \mathrm{CO}$ streams by a cryogenic separation process (Xu et al., 2014). The $\mathrm{H}_{2} / \mathrm{CO}$ stream is further separated into two parts: (i) a small fraction of hydrogen/CO $(5 \% / 5 \%)$ is injected into mixer 1 to prevent oxidation at the cathode electrode and to maintain an effective electrolysis reaction (Koh et al., 2010), and (ii) the remaining fraction is compressed by a two-stage compressor (storage pressure $30 \mathrm{~atm}$ ) before being stored in a hydrogen/synthesis gas storage tank. For the anode, a sweep gas (air) is used to evacuate the produced oxygen. An air compressor pumps the air into heat exchanger 2 for preheating by recovering heat from the anode exhaust (air with produced oxygen). The preheated air is heated up in receiver 1 up to $5 \mathrm{~K}$ below $T_{\mathrm{el}}$ and then stabilized at $T_{\mathrm{el}}$ by the electrical heater 2. A Rankine cycle with two-stage regeneration is considered,
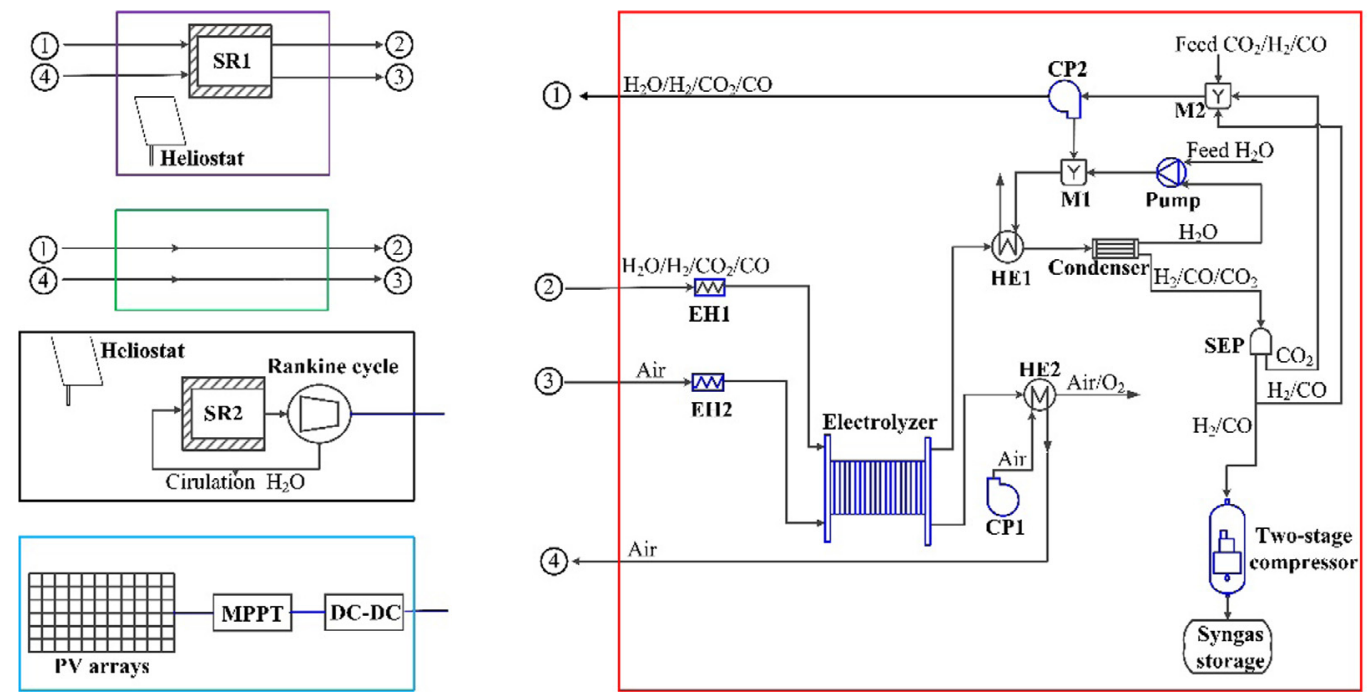
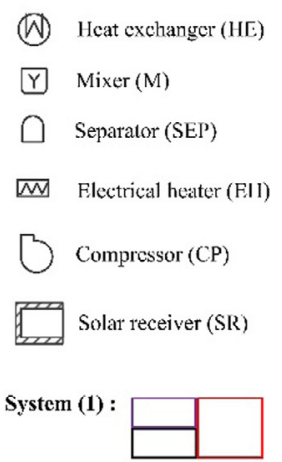

System (2) :

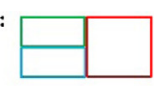

System (3) :

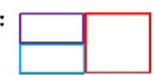

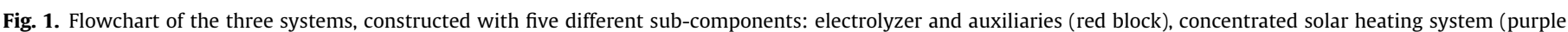

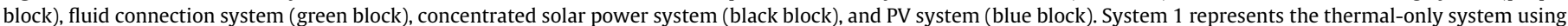

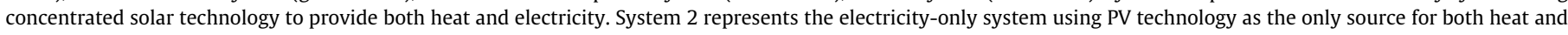

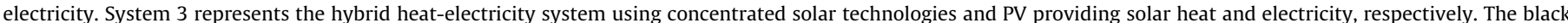

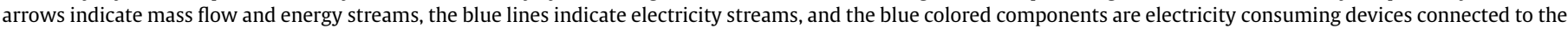
CSP or PV systems. (For interpretation of the references to color in this figure legend, the reader is referred to the web version of this article.) 
driven by a direct steam generation solar receiver (receiver 2 ). The Rankine cycle incorporates a boiler and superheater and provides the electricity to drive the electrolyzer, pumps, and compressors. The energy demand for the mixers, splitters, and separator is neglected.

System 2 is similar to system 1 with regards to the cathode and anode fluid preheating, product condensation, separation, storage, and electrolyzer operation. However, the reactant heating is solely accomplished by electrical heaters driven by the electricity generated by the PV panels. The electricity demand of the electrolyzer, pumps, and compressors is also met by PV electricity.

System 3 is also similar to system 1 with regards to the cathode and anode fluids preheating, product condensation, separation, storage, and the electrolyzer operation. However, the reactants heating is achieved by concentrated solar heat absorbed in a receiver (similar to system 1) and the electricity demand is met by PV panels (similar to system 2 ).

The scheme for the production of hydrogen only, or just $\mathrm{CO}$, is obtained by removing $\mathrm{CO}_{2} / \mathrm{CO}$ or $\mathrm{H}_{2} \mathrm{O} / \mathrm{H}_{2}$ (together with the removal of the pump and mixer 1 ), respectively (Fig. 1).

We did not consider heat storage or electricity storage components in any of the systems. The continuous production of fuel can be obtained with the current system designs without any need for additional heat or electricity storage components. Namely, the produced fuels - inherently stored energy - can be continuously released from the compressed fuel storage tank independent of the transient and cyclical solar irradiation. Our solar HTE system stores solar energy directly in the chemical bonds of the products, making additional storage not compulsory for continuous fuel delivery. The use of additional storage technologies (such as heat storage for systems 1 or 3 , or electricity storage for systems 2 and 3 ) could result in additional equipment investment cost. However, energy storage components will become important when considering the dynamic behavior of the systems. For example adding a thermal energy storage (TES) component in system 1 ensures a stable and continuous supply of heat and electricity (at smaller values than during the peak irradiation) to the receiver and electrolyzer, which will allow for a smaller design of these components and for their full load operation with reduced startup and shutdown frequencies. The latter ensures more reliable operation and smaller equipment degradation rates (especially in the electrolyzer). Overall, this could decrease the cost and increase the efficiency of the system.
For simplicity, we did not account for degradation of the components, including heliostats and receiver(s) for system 1 and system 3, PV panels for system 2 and system 3, and electrolyzer for all three systems. The electrolyzer will most likely suffer from the most severe degradation, however, it will similarly affect all three systems and therefore not alter the trends and conclusions of the study. In addition, our model only predicted the yearly-averaged system performance in which the impact of daily irradiation variation was not discussed. These two assumptions lead to underestimation of the hydrogen price and to loss in the understanding of the dynamic plant behavior.

Considering all the assumptions made in this study, we advise for careful use of the model results for absolute quantitative predictions of efficiency or cost. Instead, we emphasize trends of the system behavior and qualitative comparison among various solar energy integration strategies.

\section{Governing equations and methodology}

\subsection{Electrolyzer performance model}

The electrolyzer stack considered in this study is composed of planar solid oxide electrolysis cells (SOECs) connected in parallel. A representative SOEC model is illustrated in Fig. 2 and includes a cathode, an anode, an electrolyte, and gas channels. In the SOEC, the gas mixture $\left(\mathrm{H}_{2} \mathrm{O}, \mathrm{CO}_{2}, \mathrm{H}_{2}\right.$, and $\left.\mathrm{CO}\right)$ flows into the cathode channel, while the sweep gas (air) passes through the anode channel to remove the generated $\mathrm{O}_{2}$. In the porous cathode, $\mathrm{H}_{2} \mathrm{O}$ and $\mathrm{CO}_{2}$ diffuse through the porous electrode toward the catalysts at the cathode-electrolyte interface (considered as the triple-phaseboundary (TPB)), where $\mathrm{H}_{2} \mathrm{O}$ and $\mathrm{CO}_{2}$ molecules are split into $\mathrm{H}_{2}$, $\mathrm{CO}$, and oxygen ions according to:

$$
\begin{aligned}
& \mathrm{H}_{2} \mathrm{O}+2 \mathrm{e}^{-} \rightarrow \mathrm{H}_{2}+\mathrm{O}^{2-}, \\
& \mathrm{CO}_{2}+2 \mathrm{e}^{-} \rightarrow \mathrm{CO}+\mathrm{O}^{2-} .
\end{aligned}
$$

The produced $\mathrm{H}_{2}$ and $\mathrm{CO}$ are collected at the cathode gas channel outlet. The generated oxygen ions are transported through the electrolyte to the anode for the oxidization and the production of oxygen according to:

$$
\mathrm{O}^{2-} \rightarrow \frac{1}{2} \mathrm{O}_{2}+2 \mathrm{e}^{-}
$$

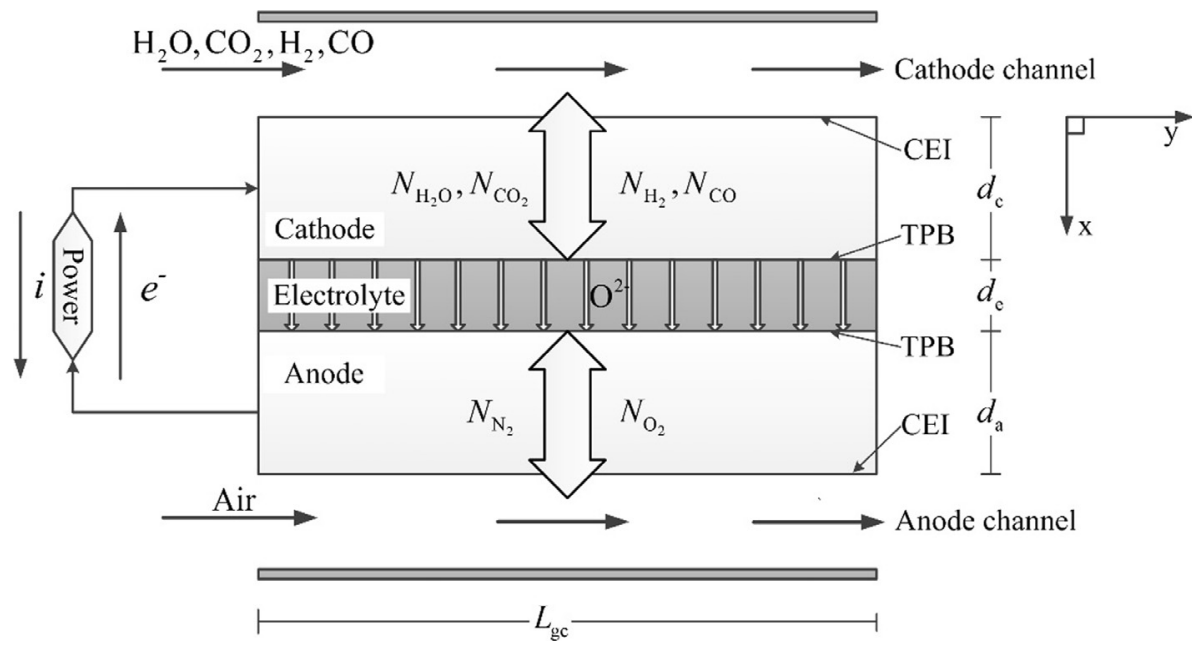

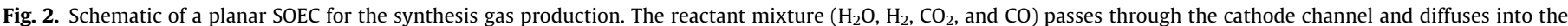

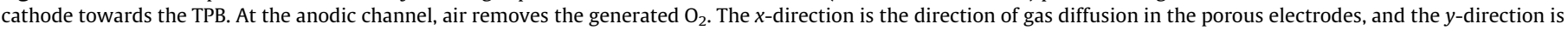
the direction of flow in the channels. The required power is provided either by CSP (system 1) or PV (systems 2 and 3 ). 
The produced oxygen is swept away by air. For the synthesis gas production, we consider the competing thermochemical water-gas shift reaction (WGSR) at the porous cathode:

$\mathrm{CO}+\mathrm{H}_{2} \mathrm{O} \rightarrow \mathrm{H}_{2}+\mathrm{CO}_{2}$.

We developed a quasi 2-dimensional model of the species transport and mass conservation in the electrolyzer cell. The model solves species transport in 1D in the gas channels (along the flow direction, $y$ ) and in the porous electrodes (transverse to the flow direction, $x$ ). The isothermal 1D channel model for the cathode and anode sides assumes plug flow, only considering convective transport in the flow direction, while neglecting species transport in the axial direction and pressure drops in the channel. The continuity equation,

$\frac{\mathrm{d} \dot{n}_{i}}{\mathrm{~d} y}=W_{\mathrm{gc}} N_{i, C E I}, \quad i=1-n_{\text {species }}$

is solved along the anodic and cathodic flow channels, with $\dot{n}_{i}$ representing the molar flow rate of species $i\left(n_{\text {species }}=2\right.$ for the anode, $n_{\text {species }}=4$ for the cathode), $W_{\mathrm{gc}}$ the width of the gas channel, and $\dot{N}_{i, \text { CEI }}$ the flux of species $i$ at the gas channel-electrode interface (CEI) as calculated by the isothermal 1D porous electrode model. This model uses the dusty-gas model (DGM) for the species transport (Bertei and Nicolella, 2015; Vural et al., 2010), and the mass conservation equation accounting for WGSR:

$\frac{\mathrm{d} N_{i}}{\mathrm{~d} x}=R_{\mathrm{WGSR}}, \quad i=1-n_{\text {species }}$,

$$
\frac{N_{i}}{D_{i, k}^{\text {eff }}}+\sum_{j \neq i}^{n} \frac{y_{j} N_{i}-y_{i} N_{j}}{D_{i j}^{\text {eff }}}=-\frac{p}{R T} \frac{\mathrm{d} y_{i}}{\mathrm{~d} x}-\frac{y_{i}}{R T_{\mathrm{el}}}\left(1+\frac{B p}{\mu D_{i, k}^{\text {eff }}}\right) \frac{\mathrm{d} p}{\mathrm{~d} x},
$$$$
i=1-n_{\text {species }},
$$

where $y_{i}$ is the molar fraction of species $i, \varepsilon$ the porosity of the electrode, $R_{\mathrm{WGSR}}$ the reaction rate of WGSR predicted by (Haberman and Young, 2004; Ni, 2012a; Ridler and Twigg, 1989), $D_{i j}^{\text {eff }}$ the effective binary diffusion coefficient of species $i$ and $j, D_{i, k}^{\text {eff }}$ the effective Knudsen diffusion coefficient of species $i, \dot{N}_{i}$ the species flux, and $B$ the electrode permeability. The binary diffusion coefficients are calculated based on the Chapman-Enskog theory, the Knudsen diffusion coefficients based on the Knudsen theory, and the diffusivities corrected by porosity-tortuosity terms to account for the porous media (effective diffusivities). The two 1D models (channel model and electrode model) are coupled through the CEI boundary. At the cathodic TPB, the molar fluxes of the species are calculated according to the current densities applied at this boundary:

$$
\begin{aligned}
& \left.\dot{N}_{\mathrm{H}_{2}}\right|_{x=d_{\mathrm{c}}}=-\frac{J_{\mathrm{H}_{2}}}{2 \mathrm{~F}},\left.\dot{N}_{\mathrm{H}_{2} \mathrm{O}}\right|_{x=d_{\mathrm{c}}}=\frac{J_{\mathrm{H}_{2} \mathrm{O}}}{2 \mathrm{~F}}, \\
& \left.\dot{N}_{\mathrm{CO}}\right|_{x=d_{\mathrm{c}}}=-\frac{J_{\mathrm{CO}}}{2 \mathrm{~F}},\left.\dot{N}_{\mathrm{CO}_{2}}\right|_{x=d_{\mathrm{c}}}=\frac{J_{\mathrm{CO}_{2}}}{2 \mathrm{~F}} .
\end{aligned}
$$
as:

The anodic TPB provides the boundary condition for the $\mathrm{O}_{2}$ flux

$$
\left.\dot{N}_{\mathrm{O}_{2}}\right|_{x=d_{c}+d_{e}}=-\frac{J_{\mathrm{CO}}+J_{\mathrm{H}_{2}}}{4 F} .
$$

The current densities in Eqs. (8) and (9) are calculated based on the developed isothermal, quasi 1-dimensional electrochemistry model of the SOEC. This model predicts the applied potential, $V_{\mathrm{el}}$, under various working conditions for a given electrode current density, $J_{\mathrm{el}}$. This model was locally solved along the channel (y-direction) using the species concentrations calculated by the quasi 2D species transport models, Eqs. (5)-(7). In this model, we considered the equilibrium voltage, $E$, and the activation and ohmic overpotentials, $\eta_{\mathrm{i}}$, resulting in the required SOEC voltage:
$V_{\mathrm{el}}=E+\eta_{\mathrm{act}, \mathrm{c}}+\eta_{\mathrm{act}, \mathrm{a}}+\eta_{\text {ohmic }} \cdot$

$E$ was predicted using Nernst's equation, considering concentration overpotentials (Salzano, 1985):

$E_{\mathrm{H}_{2}}=E_{0, \mathrm{H}_{2}}+\frac{R T_{\mathrm{el}}}{2 F} \ln \frac{p_{\mathrm{H}_{2}}^{\mathrm{TPB}}\left(p_{\mathrm{O}_{2}}^{\mathrm{TPB}}\right)^{1 / 2}}{p_{\mathrm{H}_{2} \mathrm{O}}^{\mathrm{TB}}}$,

$E_{\mathrm{CO}}=E_{0, \mathrm{CO}}+\frac{R T_{\mathrm{el}}}{2 F} \ln \frac{p_{\mathrm{CO}}^{\mathrm{TPB}}\left(p_{\mathrm{O}_{2}}^{\mathrm{TPB}}\right)^{1 / 2}}{p_{\mathrm{CO}_{2}}^{\mathrm{TPB}}}$,

where $E_{0}$ are the standard potentials $\left(E_{0, \mathrm{H} 2}=1.253-2.452 \cdot 10^{-4} T_{\mathrm{el}}\right.$ and $\left.E_{0, \mathrm{CO}}=1.46713-4.527 \cdot 10^{-4} T_{\mathrm{el}}\right)$, and $p_{i}^{\mathrm{TPB}}$ the partial pressures of $\mathrm{H}_{2}, \mathrm{O}_{2}, \mathrm{H}_{2} \mathrm{O}, \mathrm{CO}$, and $\mathrm{CO}_{2}$ at TPB. $p_{i}^{\mathrm{TPB}}$ were obtained by solving the coupled quasi $2 \mathrm{D}$ species transport models.

The Bulter-Volmer equation was used to predict the activation overpotential for $\mathrm{H}_{2}$ and $\mathrm{CO}$ production at the cathode, and for $\mathrm{O}_{2}$ production at the anode, expressed as:

$\eta_{\mathrm{act}, i, j}=\frac{R T_{\mathrm{el}}}{F} \sinh ^{-1} \frac{J_{\mathrm{el}}}{2 J_{0, i, j}}$

$J_{0, i}=\gamma_{i, j} \exp \left(-\frac{E_{\mathrm{act}, i, j}}{R T_{\mathrm{el}}}\right)$,

where $i=\mathrm{a}$ or $\mathrm{c}$, and $j=\mathrm{H}_{2}, \mathrm{CO}$, or $\mathrm{O}_{2} \cdot J_{0, i, j}$ is the exchange current density, $E_{\text {act }, i j,}$ the activation energy, and $\gamma_{i, j}$ the pre-exponential factor. The exchange current density at the cathode for $\mathrm{CO}_{2}$ splitting was taken as $40 \%$ of that of $\mathrm{H}_{2} \mathrm{O}$ splitting $\left(J_{0, \mathrm{c}, \mathrm{CO}}=0.4 J_{0, \mathrm{c}, \mathrm{H}_{2}}\right)$, and the pre-exponential factors were assumed to be equal $\left(\gamma_{c, \text { CO }}=\gamma_{c, H_{2}}\right)(\mathrm{Ni}, 2012 \mathrm{a})$. The parameter values used are listed in table 1 . The ohmic overpotential was only considered for the electrolyte since electrodes generally have much higher electrical conductivity. The ohmic overpotential is (Ferguson et al., 1996):

$\eta_{\text {ohmic }}=2.99 \cdot 10^{-5} J_{\mathrm{el}} d_{\mathrm{e}} \exp \left(\frac{10,300}{T_{\mathrm{el}}}\right)$,

where $d_{\mathrm{e}}$ is the thickness of the electrolyte.

For synthesis gas production, the two electrochemical reactions take place in parallel and, consequently, the potential of one SOEC element under a given total current density $\left(J_{\mathrm{el}}=J_{\mathrm{el}, \mathrm{CO}}+J_{\mathrm{el}, \mathrm{H} 2}\right)$ is determined by ensuring that the sum of $E_{j}+\eta_{\text {act,c, }, j}$ of the $\mathrm{H}_{2}$ and $\mathrm{CO}$ evolution reactions are equal.

The operational potential of the SOE stack is the electrode areaaveraged potential, $\left\langle V_{\mathrm{el}}\right\rangle$. The required power, $\dot{P}_{\mathrm{el}}$, of the SOE stack is:

$\dot{P}_{\mathrm{el}}=A_{\mathrm{el}} J_{\mathrm{el}}\left\langle V_{\mathrm{el}}\right\rangle$,

where $A_{\mathrm{el}}$ is the area of all cells (the single cell area is the product of $L_{\mathrm{gc}}$ and $W_{\mathrm{gc}}$ ). The heating demand of the stack was evaluated as:

Table 1

Model parameters and dimensions used in the SOEC model.

\begin{tabular}{ll}
\hline Parameters & Value \\
\hline Pre-exponential factor for anode $\left(\gamma_{\mathrm{a}, \mathrm{O} 2}\right)$ & $2.051 \cdot 10^{9} \mathrm{~A} / \mathrm{m}^{2}(\mathrm{Ni}$ et al., 2007) \\
Pre-exponential factor for cathode $\left(\gamma_{\mathrm{c}, \mathrm{H} 2}\right)$ & $1.344 \cdot 10^{10} \mathrm{~A} / \mathrm{m}^{2}(\mathrm{Ni}$ et al., 2007) \\
Activation energy for anode $\left(E_{\mathrm{act}, \mathrm{a}, \mathrm{O} 2}\right)$ & $1.2 \cdot 10^{5} \mathrm{~J} / \mathrm{mol}(\mathrm{Ni}$ et al., 2007) \\
Activation energy for cathode $\left(E_{\mathrm{act}, \mathrm{c}, \mathrm{H} 2}\right)$ & $1.0 \cdot 10^{5} \mathrm{~J} / \mathrm{mol}(\mathrm{Ni}$ et al., 2007$)$ \\
Average pore radius $\left(r_{\mathrm{p}}\right)$ & $1.07 \mu \mathrm{m}(\mathrm{Ni}$ et al., 2007) \\
Electrode tortuosity $(\xi)$ & $5.4(\mathrm{Ni}$ et al., 2007) \\
Electrode porosity $(\phi)$ & $0.48(\mathrm{Ni}$ et al., 2007) \\
Electrolyte thickness $\left(d_{\mathrm{e}}\right)$ & $50 \mu \mathrm{m}$ (Momma et al., 1997) \\
Cathode thickness $\left(d_{\mathrm{c}}\right)$ & $100 \mu \mathrm{m}$ (Momma et al., 1997) \\
Anode thickness $\left(d_{\mathrm{a}}\right)$ & $50 \mu \mathrm{m}$ (Momma et al., 1997) \\
Gas channel length $\left(L_{\mathrm{gc}}\right)$ & $0.05 \mathrm{~m}$ (Menon et al., 2015) \\
Gas channel width $\left(W_{\mathrm{gc}}\right)$ & $0.001 \mathrm{~m}$ (Menon et al., 2015) \\
\hline
\end{tabular}


$Q_{\mathrm{el}}=A_{\mathrm{el}} J_{\mathrm{el}}\left(V_{\mathrm{tn}}-\left\langle V_{\mathrm{el}}\right\rangle\right)$

where $V_{\mathrm{tn}}$ is the thermoneutral voltage for a given $T_{\mathrm{el}}$. For $V_{\mathrm{tn}}<\left\langle V_{\mathrm{el}}\right\rangle$, $\dot{Q}_{\mathrm{el}}=0$, assuming effective electrolyzer cooling. This heat is either provided by the electrical heaters (system 2 ) or by the solar receiver (systems 1 and 3).

Both, the quasi 2D species transport and conservation model and the quasi 1D electrolyzer model were solved in Matlab. The DGM equations were solved by a Matlab boundary value solver (bp4c), based on a collocation numerical method (Shampine et al., 2000). Following a mesh independent study with a relative error tolerance of $10^{-3}$ for species flux, molar fractions, and pressure, we used ten uniform mesh elements along the $x$-axis for each electrode, and ten uniform elements along the $y$-axis for both fluid channels and electrodes. The electrolyzer model was validated with experimental data in the literature and the details are in the supporting information for hydrogen generation (Fig. S2a) and syngas production (Fig. S2b). All reference cell parameters and properties used in the model are listed in Table 1.

\subsection{CSP performance model}

For the CSP model, we utilize a point-concentrating solar tower system for the production of high-temperature heat. The heliostat field's annual optical efficiency was assumed to be $64 \%$ based on data from the $11 \mathrm{MW}_{\mathrm{el}}$ power tower PS10 located in Andalusia, Spain (Kistler, 1986).

Here we introduce two sub-models: (i) a solar receiver model, and (ii) a Rankine cycle model. We consider two types of receivers: (i) a receiver for the high temperature reactant and sweep gas heating, and (ii) a receiver for high temperature and high pressure steam generation for the power cycle. The receiver is a cylindrical cavity receiver with a circular aperture area through which the concentrated solar radiation enters. The energy transferred to the fluids $\left(\mathrm{H}_{2}, \mathrm{CO}, \mathrm{H}_{2} \mathrm{O}, \mathrm{CO}_{2}\right.$, and air) was calculated by considering the energy balance of the receiver. The working fluids in the power unit $\left(\mathrm{H}_{2} \mathrm{O}\right)$ and the electrolyzer $\left(\mathrm{H}_{2}, \mathrm{CO}, \mathrm{H}_{2} \mathrm{O}, \mathrm{CO}_{2}\right.$, and air) were directly heated by the solar receiver without considering an intermediate heat transfer fluid (such as synthetic oil or molten salts) and a subsequent heat exchanger. This choice was made in order to increase the efficiency and keeping system complexity low. We only considered radiative and convective heat losses. Conductive heat losses were neglected. The energy balance of the receiver is given by:

$\dot{Q}_{\text {fluid }}=\dot{Q}_{\text {aperture }}-\dot{Q}_{\text {rad }}-\dot{Q}_{\text {conv }}$,

where $\dot{Q}_{\text {fluid }}$ represents the sensible and latent energy transferred to the working fluid, $\dot{Q}_{\text {aperture }}$ the energy arriving at the receiver aperture, $\dot{Q}_{\text {rad }}$ the radiative heat loss form the aperture,

$\dot{Q}_{\text {rad }}=\varepsilon_{\text {apparent }} \sigma \pi r_{\mathrm{ap}}^{2}\left(T_{\mathrm{re}, \mathrm{av}}^{4}-T_{0}^{4}\right)$,

and $\dot{Q}_{\text {conv }}$ the combined natural and forced convection heat losses,

$\dot{Q}_{\text {conv }}=\left(\pi r_{\text {ap }}^{2}+2 \pi r_{\text {ap }} L_{\text {re }}\right) h_{\text {conv }}\left(T_{\text {re }, \text { av }}-T_{0}\right)$.

The heat transfer coefficient, $h_{\text {conv }}$, was evaluated from empirical correlations considering natural and forced convection (Neises and Wagner, 2012; Wagner, 2008). The cavity length was $L_{\mathrm{re}}=3 r_{\mathrm{ap}}$. The power from the heliostat field was given as a function of the aperture radius, $r_{\mathrm{ap}}$ :

$\dot{Q}_{\text {aperture }}=\pi r_{\mathrm{ap}}^{2} \cdot \mathrm{DNI} \cdot \mathrm{CR}$,

$\mathrm{CR}=\frac{A_{\text {heliostat }}}{\pi r_{\mathrm{ap}}^{2} \eta_{\mathrm{opt}}}$ where CR is the effective concentration ratio. $\dot{Q}_{\text {rad }}$ was calculated by:

$\dot{\mathrm{Q}}_{\text {rad }}=\varepsilon_{\text {apparent }} \pi r_{\mathrm{ap}}^{2}\left(T_{\mathrm{re}, \mathrm{av}}^{4}-T_{0}^{4}\right)$,

using an apparent emissivity, $\varepsilon_{\text {apparent }}$ (a constant determined by the $L_{\mathrm{re}} / r_{\mathrm{ap}}$ ratio and the material emissivity) (Howell et al., 2010), and the averaged fluid temperature, $T_{\mathrm{re}, \mathrm{av}}=1 / 2\left(T_{\mathrm{f}, \mathrm{in}}+T_{\mathrm{f}, \mathrm{out}}\right)$. The receiver's thermal efficiency is defined as the ratio of $\dot{Q}_{\text {fluid }}$ to $\dot{Q}_{\text {rad }}$. We validated our receiver model with literature data (Sanz-Bermejo et al., 2014a). The solar receiver thermal efficiency for our reference case for system 1 with a mean temperature of $727 \mathrm{~K}$ was $82 \%$ (see Section 4.2 ) which agreed with the efficiency of $81.7 \%$ reported in (Sanz-Bermejo et al., 2014a) for their superheating receiver with a mean temperature of $736 \mathrm{~K}$.

A Rankine cycle with two-stage regeneration was used (Cengel et al., 2002). The inlet temperature and pressure of the turbine was $823 \mathrm{~K}$ and $70 \mathrm{~atm}$, and the back pressure was $1 \mathrm{~atm}$. The two steam extraction pressures were $30 \mathrm{~atm}$ and $5 \mathrm{~atm}$. A separate solar receiver was used for power generation. Solar receiver size and the additional size of the solar field were calculated according to the aforementioned receiver model with the exception that the fluid properties were different at the different operational pressures. The total electricity demand provided by the CSP sub-system of

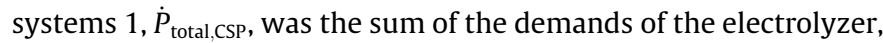
pumps, compressors, and electrical heaters.

\subsection{Photovoltaic cell array performance model}

An equivalent circuit model for the individual PV modules was used to predict module current-voltage $(I-V)$ characteristics based on the data provided by the manufacturer: the open circuit voltage, $V_{\mathrm{oc}}$, the short circuit current, $I_{\mathrm{sc}}$, the maximum power current and voltage, $I_{\mathrm{mp}}$ and $V_{\mathrm{mp}}$, and the temperature coefficients of the open circuit voltage and short circuit current, $\beta_{V o c}$ and $\alpha_{I s c}$. The circuit accounted for series and shunt resistances, $R_{\mathrm{S}}$ and $R_{\mathrm{sh}}$ (De Soto et al., 2006):

$I_{\mathrm{PV}}=I_{\mathrm{L}}-I_{0}\left(e^{\frac{V+I R_{\mathrm{S}}}{a}}-1\right)-\frac{V_{\mathrm{PV}}+I_{\mathrm{PV}} R_{\mathrm{S}}}{R_{\mathrm{Sh}}}$,

$a=\frac{N_{s} n_{\mathrm{I}} k T_{\mathrm{PV}}}{q}$,

$T_{\mathrm{PV}}=T_{0}+\frac{(D N I+D H I)\left(T_{\text {noct }}-T_{0}\right)}{\left(D N I_{0}+D H I_{0}\right)+6.62\left(v-v_{0}\right)\left(T_{\text {noct }}-T_{0}\right)}$,

where $I_{\mathrm{L}}$ is the light current, $I_{0}$ the diode reverse saturation current, $a$ the modified ideality factor, $N_{\mathrm{s}}$ the number of cells in series in each PV module, $T_{\mathrm{PV}}$ the cell temperature, and $n_{\mathrm{I}}$ the ideality factor. In Eq. (24), $T_{\mathrm{PV}}$ is given as a function of the nominal cell temperature, $T_{\text {noct }}=317 \mathrm{~K}$, nominal direct normal irradiance, $D N I_{0}$, nominal diffuse horizontal irradiance, $D \mathrm{HI}_{0}$, nominal wind speed, $v_{0}$, ambient temperature, $T_{0}$, operating $D N I$ and $D H I \quad(D H I=0.165 \cdot D N I /$ $(1-0.165)$ (Duffie and Beckman, 2013)), and operating wind speed, $v$ (Bizzarri et al., 2013). The detailed calculation procedures for the parameters are detailed in (De Soto et al., 2006). We used a monocrystalline Si PV module (Sunpower SPR-210-BLK-U) for our investigation with module characteristics from Gilman et al. (Gilman and Dobos, 2012), tabulated in Table S1. The validation of the PV model was conducted under nominal conditions and the comparison between the simulated data and the reference curve of the provider shows good agreement (Fig. S1). We assumed $v=3 \mathrm{~m} / \mathrm{s}$. Two-axis tracking was considered for the PV panels, maximizing the optical efficiency of the PV system. The total electricity demand of the PV array, $\dot{P}_{\text {total pv }}$, for both systems 2 and 3, was the sum of the demands of the electrolyzer, pumps, compressors, and 
electrical heaters (heaters for system 2 and temperature stabilizer for system 3 ). Hence, the total PV panel area is given by:

$A_{\mathrm{PV}, \text { array }}=\frac{A_{\mathrm{PV}} \dot{P}_{\text {total }, \mathrm{PV}}}{I_{\mathrm{PV}} V_{\mathrm{PV}}}$,

where $A_{\mathrm{PV}}$ is the PV module area. To make use of the maximum but varying power generated by the PV module arrays, the PV system used a maximum power point tracker (MPPT) with a full sun tracking system. Additionally, a DC-DC converter was used. The efficiency of the MPPT and the DC-DC converter were each assumed to be $95 \%$ (Gibson and Kelly, 2008).

\subsection{Auxiliary devices}

Heat exchangers were modeled in a counter flow manner with the temperature of the hot and cold streams predicted by the energy balance equation assuming a range of heat recovery effectiveness, $\varepsilon_{\mathrm{HE}}$. For heat exchanger 1 (HE1), we assumed that only the sensible heat of the exhaust stream could be recovered. In order to calculate log mean temperature differences and required heat exchanger surface areas of the cold stream undergoing phase change, heat transfer was divided into subcooled, two-phase, and superheating regions. The overall heat transfer coefficient, $U$, for each region was assumed to be constant $\left(U=500 \mathrm{~W} / \mathrm{m}^{2} \mathrm{~K}\right.$ for liquid-liquid heat exchange, $U=200 \mathrm{~W} / \mathrm{m}^{2} \mathrm{~K}$ for gas-gas heat exchange, and $U=2000 \mathrm{~W} / \mathrm{m}^{2} \mathrm{~K}$ for the two-phase region (Lienhard, 2013)). The electricity demand of pumps and compressors was estimated assuming isentropic compression with isentropic efficiencies of 0.8 and mechanical efficiencies of 0.9 . The energy consumption of mixers, splitters, and separators were neglected.

The cost of separating $\mathrm{CO}_{2}$ from the produced gases was assumed to be $\$ 10.28 / \mathrm{tCO}_{2}$ based on a multi-stage compression, refrigeration and cryogenic separation processes (Xu et al., 2014). These costs were added to $C_{\text {feed }}$ (see section 3.6). The energy consumption of this process was $0.45 \mathrm{MJ} / \mathrm{kgCO}_{2}$ and was neglected in the calculations as it was always smaller than the energy requirements for the pumps and compressors. This led to a slight overestimation of the plant efficiency (maximum overestimation of about $16 \%)$.

\subsection{System efficiency definition}

The overall solar-to-fuel efficiency of the system is defined as the ratio of the energy content of the products to the overall incident solar radiation and the energy content of the fed feedstock:

$\eta_{\mathrm{STF}}=\frac{\dot{n}_{\mathrm{H}_{2}} H H V_{\mathrm{H}_{2}}+\dot{n}_{\mathrm{CO}} H H V_{\mathrm{CO}}}{(D N I+D H I)\left(A_{\mathrm{PV}, \text { arrary }}+A_{\text {heliostat }}\right)+\dot{n}_{\mathrm{H}_{2}, \text { feed }} H H V_{\mathrm{H}_{2}}+\dot{n}_{\mathrm{CO}, \text { feed }} H H V_{\mathrm{CO}}}$.

We used the high heating value (HHV) of each of the products and feed streams.

\subsection{Cost model of the systems}

The cost model considered investment and operating cost for the major components of the three systems. The cost of the photovoltaic system depends on the unit cost of the module, which itself depends on the choice of module material. The price for monocrystalline Sibased modules is $\$ 1.24 / \mathrm{W}$ (Gilman and Dobos, 2012). The tracking and other auxiliary equipment cost was considered to be $40 \%$ of the total PV system cost (Gielen, 2012), resulting in total PV cost of

$C_{\mathrm{PV}}=\frac{C_{\text {module }}^{*} \dot{P}_{\text {total,PV }}}{0.6}$.

The cost of the electrolyzer unit per unit area was $\$ 1695 / \mathrm{m}^{2}$ (Fu et al., 2010) and a similar cost value $\left(\$ 1555 / \mathrm{m}^{2}\right)$ was reported by
(Milobar et al., 2015). In addition, a recent paper by (Ferrero et al., 2016) showed that the SOFC stack cost is expected to drop 10 times by 2030 compared with 2013 . Here, we took $\$ 1695 / \mathrm{m}^{2}$ as the reference case value. The effect of the SOEC stack cost on the hydrogen production price was investigated with a sensitivity study and the results are shown in Fig. S3. This total electrolyzer unit cost consisted of the stack (46\%), the balance of plant (21\%), and the power electronics and gas conditioning (33\%) (Saur, 2008),

$C_{\mathrm{el}}=\frac{C_{\mathrm{unit}}^{\prime \prime} A_{\mathrm{el}}}{0.46}$

The cost of the concentrated solar power system consisted of four major parts: solar tower, heliostat field, receiver, and power unit, with the heliostat field the major fraction of the cost (Singer et al., 2010):

$C_{\text {heliostat }}=3951.8 A_{\text {heliostat }}^{0.7}$,

$C_{\text {tower }}=4785 H_{\text {tower }}-10.51 A_{\text {heliostat }}+0.608 H_{\text {tower }} A_{\text {heliostat }}-82740$,

$C_{\text {receiver }}=0.5224 \dot{Q}_{\text {fluid }}^{0.93}$,

$C_{\text {powerunit }}=2.7164 \dot{P}_{\text {CSP }}^{0.93}$

For the hybrid system (system 3), the power unit is not present and is therefore not included. For the thermal only system (system 1 ), the receiver cost is counted twice and the cost of each receiver is calculated according to the energy delivered $\left(\dot{Q}_{\text {fluid }}\right)$.

The land cost of the required PV plant and/or CSP plant areas is calculated by considering a land use factor of 0.35 and land unit cost of $\$ 2 / \mathrm{m}^{2}$ (Meier et al., 2005),

$C_{\text {land }}=\frac{2\left(A_{\mathrm{PV}, \text { array }}+A_{\text {heliostat }}\right)}{0.35}$.

Costs of the heat exchangers were derived from the total area of the heat exchanger (Myers et al., 2002),

$C_{\mathrm{HE}}=2.78 \times 10^{3.6788+0.4412 \log A_{\mathrm{HE}}}$.

The costs of auxiliary devices such as pumps, compressors, and mixers were calculated based on available references (Meier et al., 2005; Rivera-Tinoco et al., 2010). The costs of auxiliary devices and the heat exchangers were lumped into one term, $C_{\text {other }}$.

The direct investment cost is the sum of the equipment,

$C_{\mathrm{d}, \text { total }}=\left(C_{\mathrm{PV}}+C_{\mathrm{el}}+C_{\text {heliostat }}+C_{\text {tower }}+C_{\text {receiver }}+C_{\text {powerunit }}+C_{\text {land }}+C_{\text {other }}\right)$.

The indirect investment cost, $C_{\text {ind,total, }}$ for engineering, procurement, commissioning, and management were considered to be $20 \%$ of the initial direct capital cost, except for the heliostat costs, for which only $10 \%$ indirect investment costs were assumed (Meier et al., 2005). Additionally, a $15 \%$ contingency cost, $C_{\text {contingency, was }}$ added to the total investment cost.

The maintenance cost, $C_{\mathrm{m}}$, was included, assumed as equal to $4 \%$ of the total investment cost. The feedstock costs (feed $\mathrm{H}_{2} \mathrm{O}$ and $\left.\mathrm{CO}_{2}\right), C_{\text {feed, }}$, were based on a specific cost for $\mathrm{CO}_{2}$ of $\$ 0.1808 / \mathrm{kg}$ and for $\mathrm{H}_{2} \mathrm{O}$ of $\$ 0.001 / \mathrm{kg}$ (Fu et al., 2010), multiplied by the quantity required over the lifetime.

The total plant cost, $C_{\text {total }}$, is the sum of all the costs: investment, indirect, contingency, maintenance, and feed. The interest rate, $i$, was assumed to be $6 \%$ and a life time, $t$, of 25 years was chosen. The total annual cost including interest is

$C_{\text {annual,total }}=\frac{i(1+i)^{t} C_{\text {total }}}{(1+i)^{t}-1}$ 
Table 2

Reference parameters and parameter ranges considered in the techno-economic model for the three systems.

\begin{tabular}{lll}
\hline Parameters & Value & $\begin{array}{l}\text { Reference } \\
\text { case }\end{array}$ \\
\hline Operation temperature for electrolyzer, $T_{\mathrm{el}}$ & $1000 \mathrm{~K}$ \\
Operation pressure for electrolyzer, $p_{\mathrm{el}}$ & $800-1500 \mathrm{~K}$ & $10 \mathrm{~atm}$ \\
Operation current density, $J_{\mathrm{el}}$ & $1-25 \mathrm{~atm}$ & $5000 \mathrm{~A} / \mathrm{m}^{2}$ \\
& $1000-10,000$ & 0.165 \\
Diffuse solar irradiation ratio, $R_{\mathrm{HN}}=D H I /(D N I+D H I)$ & $\mathrm{A} / \mathrm{m}^{2}$ & $800 \mathrm{~W} / \mathrm{m}^{2}$ \\
Direct normal insolation, $D N I$ & $100-1000 \mathrm{~W} / \mathrm{m}^{2}$ & 0.8 \\
Heat exchanger effectiveness, $\varepsilon_{\mathrm{HE}}$ & $0.1-0.98$ & 0.2 \\
Water conversion extent, $W_{\mathrm{ce}}$ & $0.1-1$ & \\
\hline
\end{tabular}

The levelized cost of fuel was calculated considering a target daily hydrogen production,

$C_{\text {fuel }}=\frac{C_{\text {annual,total }}}{365 \dot{m}_{\text {fuel }}}$.

The plant was assumed to continuously operate for $8 \mathrm{~h}$ a day, producing $400 \mathrm{~kg} \mathrm{H}_{2}$ per day. For synthesis gas production, we assumed a production of $400 \mathrm{~kg} \mathrm{H}_{2}$ plus $4400 \mathrm{~kg} \mathrm{CO}$, equivalent to a molar ratio of $\mathrm{H}_{2} / \mathrm{CO}=2$.

\section{Results and discussion}

\subsection{Reference case comparison of the three systems}

We conducted a detailed performance and cost analysis for the three proposed systems under various design and operational conditions. The simulated reference parameters and parameter ranges for the sensitivity analysis are listed in the table 2 . The reference case is for water electrolysis and the production of hydrogen only. The operation temperature was chosen based on experimental data (Laguna-Bercero, 2012; Momma et al., 1997; Sapountzi et al., 2017) and was pushed to values above the typically used $1273 \mathrm{~K}$ (all the way up to $1500 \mathrm{~K}$ ), in order to explore high temperature benefits potentially guide future electrolyzer development. The current density range was chosen based on experimental data (Fang et al., 2015; Knibbe et al., 2010; Zhan et al., 2009). The reference irradiation magnitude chosen corresponds to the yearly averaged DNI (over 8 operational hours a day) of potential plant locations already used for commercial solar electricity production. For example, Sevilla, Southern Spain $\left(636 \mathrm{~W} / \mathrm{m}^{2}\right.$, from Helioclim-3 database) or Barstow, CA, USA $\left(932 \mathrm{~W} / \mathrm{m}^{2}\right.$, from NREL's TMY3 datasets).

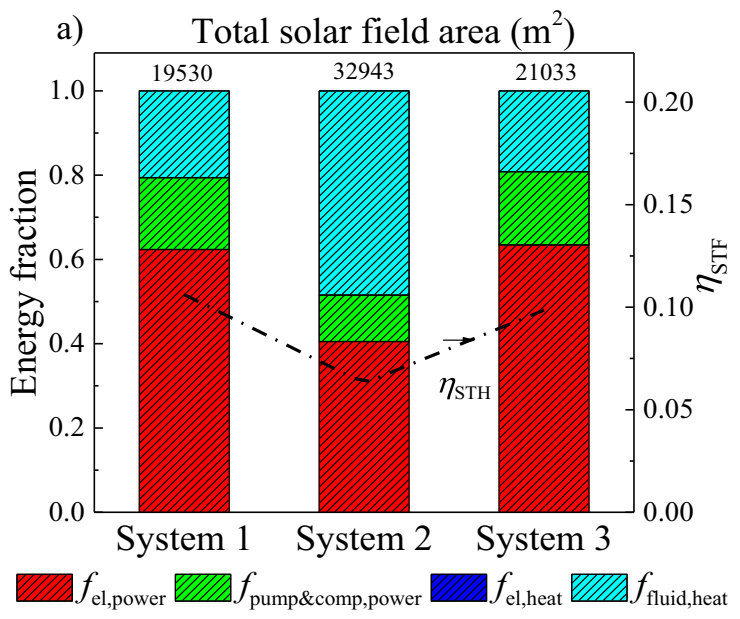

The dynamic behavior of the plant was not captured as we used a steady-state yearly averaged performance model. This will lead to an underestimation of the effective fuel cost and overestimation of the plant efficiency given that - without any intermediate storage options in the system, such a TES - the various components will be exposed to non-ideal operating conditions (including unsteady operation, part load operation, and more frequent startup and shutdown) with the potential for increased degradation, and will operate at low capacity factors.

Fig. 3 compares the three proposed systems at the reference state in terms of energy conversion efficiency, $\eta_{\mathrm{STF}}$, and cost, $C_{\text {fuel }}$. $f_{\text {el,power }}$ represents the fraction of the power of the system used to drive the electrolyzer, $f_{\text {pump\&comp,power }}$ is the fraction of power to drive the pumps and compressors, $f_{\mathrm{el}, \text { heat }}$ is the heating demand of the electrolyzer (under endothermal operation), and $f_{\text {fluid,heat }}$ is the heating power for reactants and sweep gas. The detailed definition of $f_{\mathrm{i}}$ is given in Table S2. System 1 showed the largest efficiency $(10.6 \%)$, but at the highest hydrogen cost $(\$ 8.19 / \mathrm{kg})$. This is explained by the concentrated solar power sub-system, which is more expensive than the PV sub-system, leading to much higher annual costs $(\$ 1,195,212$ for system 1$)$ compared to system 2 $(\$ 1,171,393)$ and system $3(\$ 917,506)$. System 2 showed the lowest efficiency $(6.3 \%)$, but with a lower fuel cost $(\$ 8.02 / \mathrm{kg})$ compared to system 1 . The low efficiency results from the low efficiency of heat produced by PV-electricity and subsequent electrical heaters (together 13.6\%) compared to the high efficiency of concentrated solar heating (52.6\% solar-to-heat efficiency in the receiver). Employing PV for heating led to a $48.5 \%$ occupation of the solar field for heating purposes, represented by $f_{\text {fluid,heat. }}$ System 3 , the hybrid system, exhibited both advantages: the high heating efficiency (52.6\%) of system 1 , resulting in $\eta_{\mathrm{STF}}=9.9 \%$, and the

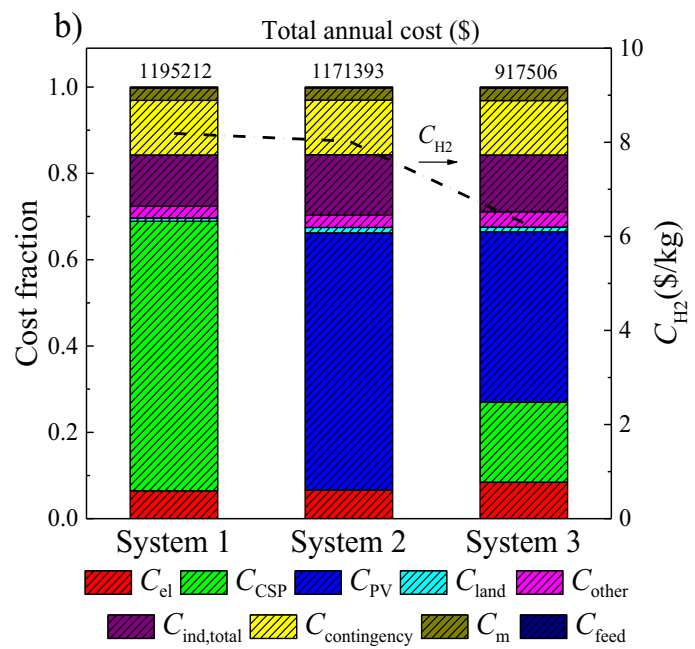

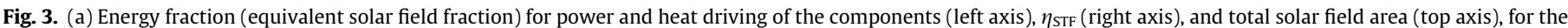

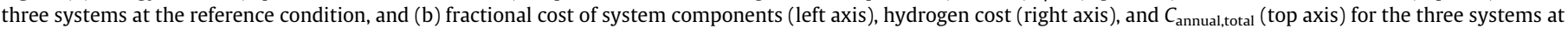
the reference condition. 

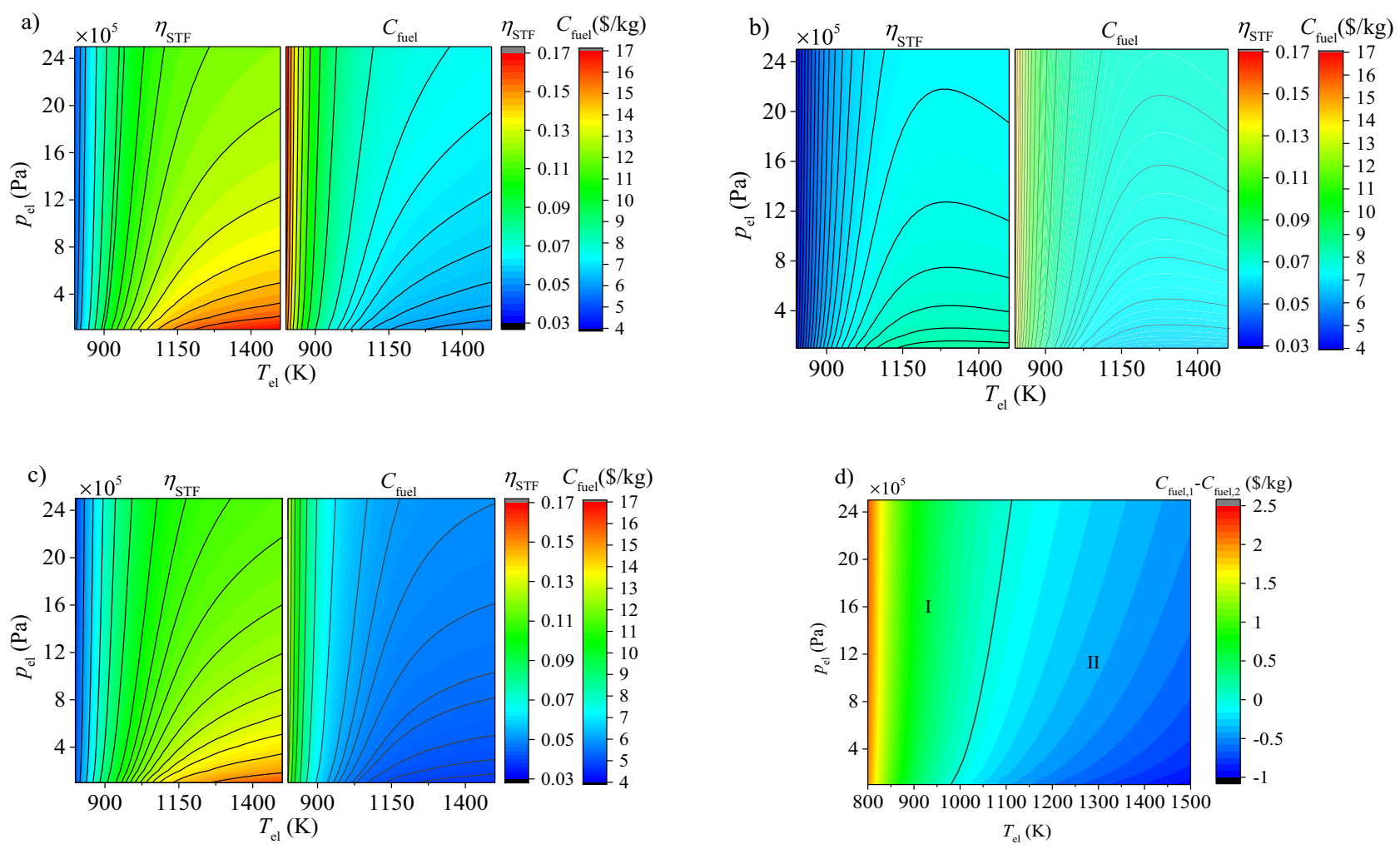

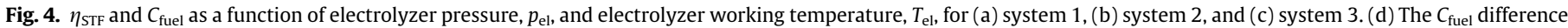

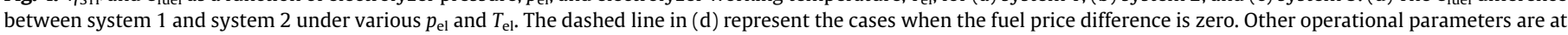
the reference state (Tables 1 and 2).

low cost of system 2 , resulting in $C_{\text {fuel }}=\$ 6.28 / \mathrm{kg}$. System 3 is less expensive than system 2 , resulting from a dramatically reduced energy fraction needed for heating, $f_{\text {fluid,heat }}+f_{\text {el,heat }}$, $(48.5 \%$ for system 2 and 19.2\% for system 3). This is due to the higher heating efficiency of the concentrated solar technology compared to the PV technology even with a higher cost for concentrated solar. $f_{\text {el,heat }}$ is zero for the reference cases, as the operation is exothermic. $\left\langle V_{\mathrm{el}}\right\rangle$ is $1.31 \mathrm{~V}$ for all systems, which is $0.03 \mathrm{~V}$ larger than the thermoneutral voltage (equals $1.28 \mathrm{~V}$ ). The reference case results predicted competitive hydrogen prices (especially for system 3 ) compared with other solar hydrogen and fuel processing technologies such as PV and PEM electrolyzers $(\$ 9.1-12.1 / \mathrm{kg})$, photoelectrochemical cells (PEC) $(\$ 11.4 / \mathrm{kg})$, or solar thermochemical redox cycles $(\$ 8.3 / \mathrm{kg})$. Note that these prices were taken from the base case data discussed in Shaner et al. (2016) and Abanades et al. (2013).

A comparatively high solar-to-fuel efficiency and low levelized fuel cost provides the main rational for utilization of the hybrid PV-CSP approach (system 3), providing a promising pathway for scaled solar fuel processing by HTE. In order for system 1 to be competitive with system 2 , the concentrated solar power subcomponent cost would need to be reduced by $2.3 \%$.

\subsection{Effect of the diffuse irradiation ratio}

Since the composition of solar irradiation (ratio $R_{\mathrm{HN}}=D H I /(D N I$ $+D H I)$ ) varies according to time, weather, and plant location, the impact on the $\eta_{\text {STF }}$ and $C_{\text {fuel }}$ for different systems is different depending on whether the system utilizes the $D H I$ part of solar irradiation. A study of the impact of $R_{\mathrm{HN}}$ on system performance was carried out at the reference case condition for each of the three proposed systems. The total solar irradiation $(D N I+D H I)$ was held at $958 \mathrm{~W} / \mathrm{m}^{2}$ (at the reference case) and only $R_{\mathrm{HN}}$ was varied. For system $1, \eta_{\mathrm{STF}}$ reduced from $10.6 \%$, at the reference condition, to $6.3 \%$ (equivalent to the efficiency for system 2 at the reference condition) as $R_{\mathrm{HN}}$ increased from 0.165 (reference value) to 0.499 . $C_{\text {fuel }}$ increased from $\$ 8.19 / \mathrm{kg}$ to $\$ 9.75 / \mathrm{kg}$ accordingly ( $\$ 5.31 / \mathrm{kg}$ for system 2 at reference conditions). This illustrates that system 1 is superior to system 2 in terms of $\eta_{\mathrm{STF}}$ only when $R_{\mathrm{HN}}$ is smaller than 0.499 , while $C_{\text {fuel }}$ is always inferior for system 1 . System 3 shows the same $\eta_{\mathrm{STF}}$ as system $2\left(\eta_{\mathrm{STF}}=6.3 \%\right)$ when $R_{\mathrm{HN}}=0.783$ at $C_{\text {fuel }}=\$ 8.09 / \mathrm{kg}$. System 3 shows equivalent $C_{\text {fuel }}$ with system $2\left(C_{\text {fuel }}=\$ 8.02 / \mathrm{kg}\right)$ when $R_{\mathrm{HN}}=0.777$ at $\eta_{\mathrm{STF}}=6.39 \%$. As long as $R_{\mathrm{HN}}<0.777$, system 3 is superior to system 2 in terms of $\eta_{\mathrm{STF}}$ and $C_{\text {fuel. }}$.

\subsection{Effects of electrolyzer operating temperature and pressure}

The operating temperature of the electrolyzer is one of the key factors in determining the operating voltage of the electrolyzer, which in turn determines electrolyzer heating and power demands. Fig. 4 shows $\eta_{\text {STF }}$ and $C_{\text {fuel }}$ for various operating $T_{\mathrm{el}}$ and $p_{\mathrm{el}}$ combinations for the three different systems with other parameters held at reference values (Tables 1 and 2).

For system 1, higher $T_{\mathrm{el}}$ always leads to larger $\eta_{\mathrm{STF}}$ for all studied pressures. The increase in $\eta_{\mathrm{STF}}$ with increasing $T_{\mathrm{el}}$ results from the reduced $\left\langle V_{\text {el }}\right\rangle$ at high temperatures, while this increase in $\eta_{\text {STF }}$ with increasing $T_{\mathrm{el}}$ is reduced as a result of the increased heating demand $\left(\dot{Q}_{\text {fluid }}\right)$ and solar receiver heat losses $\left(\dot{Q}_{\text {rad }}\right.$ and $\left.\dot{Q}_{\text {conv }}\right)$. Higher $p_{\mathrm{el}}$ always caused a drop in $\eta_{\text {STF }}$ due to a significant increase in pumping power for the reactants and sweep gas. Similar trends were found for $C_{\text {fuel }}$ with respect to $T_{\mathrm{el}}$ and $p_{\mathrm{el}}$, where higher $\eta_{\mathrm{STF}}$ led to smaller-sized CSP sub-systems which, in turn, lowered the $C_{\text {fuel }}$.

For system 2, the optimal $T_{\mathrm{el}}$ for various $p_{\mathrm{el}}$ was $1300 \mathrm{~K}$. The increase in $\eta_{\mathrm{STF}}$ with increasing $T_{\mathrm{el}}$ results from the domination of reduced $\left\langle V_{\mathrm{el}}\right\rangle$ at high temperatures. While this increase in $\eta_{\mathrm{STF}}$ 

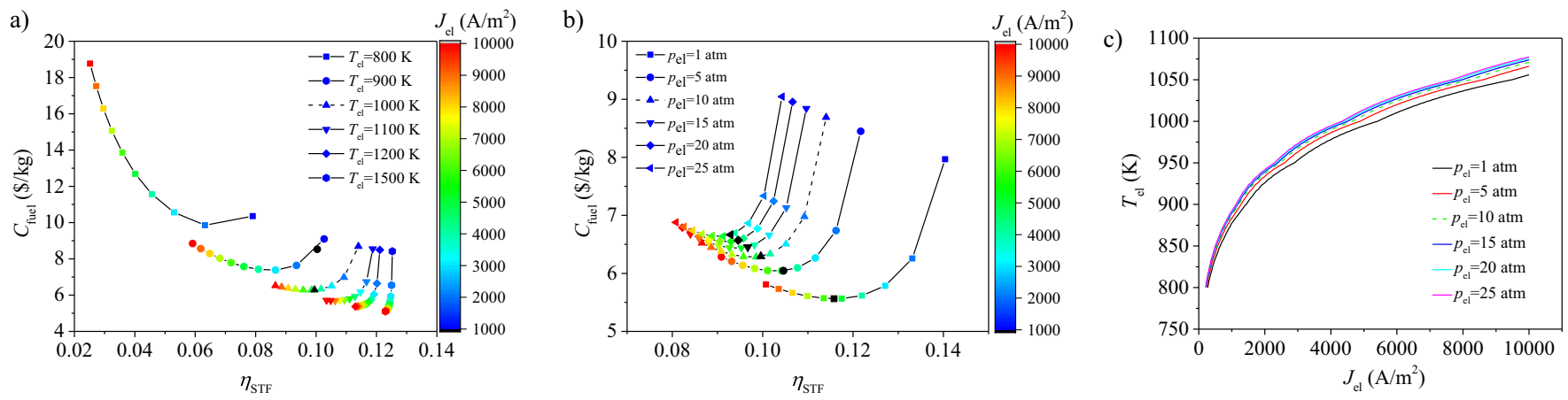

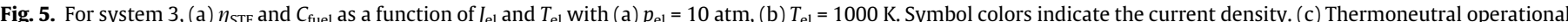

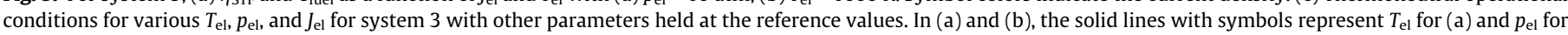

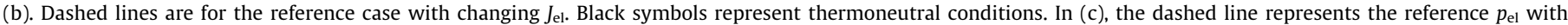
changing $J_{\mathrm{el}}$.

is counteracted with further increase in $T_{\mathrm{el}}$ resulting from an increasing heat demand at increased $T_{\mathrm{el}}$. The penalty of increased heat demand induced by increasing $T_{\mathrm{el}}$ is more significant for system 2 than for system 1 at the same temperature, as the former has a lower heating efficiency. For system 2 at the same conditions, the $\eta_{\text {STF }}$ is significantly reduced compared to system 1 . Due to this low heat efficiency, system 2 could result in even larger $C_{\text {fuel }}$ compare to system 1 (Fig.4d) at larger $T_{\mathrm{el}}$. For example, system 2 shows slightly smaller fuel cost than system 1 at reference conditions (in section I), while this advantage in fuel cost is counteracted when $T_{\mathrm{el}}$ is larger than $1050 \mathrm{~K}$ (in section II) with other parameters kept at reference conditions. In addition, the transition $T_{\mathrm{el}}$ between section I and section II increases with increasing $p_{\mathrm{el}}$ due to increased electricity demand with increasing $p_{\mathrm{el}}$ which alleviates the effect of lower heating efficiency. System 2 showed similar trends as system 1 in terms of cost and efficiency variations with increasing pressure.

The $\eta_{\text {STF }}$ of the hybrid system (system 3 ) showed the same variations with changing $T_{\mathrm{el}}$ and $p_{\mathrm{el}}$, but at slightly lower values than system 1 , due to the slightly lower solar-to-electricity efficiency of system 3 (15.2\%) compared to system $1(15.8 \%)$ at the reference condition. For system 3, the solar-to-electricity efficiency is $15.2 \%$ for the reference case, as a result of the monocrystalline silicon PV cell used in this study. For system 1, the solar-to-electricity efficiency ( $15.8 \%$ for the reference case) is a product of the solar-tothermal efficiency (52.6\% for the reference case) and the power unit efficiency (30\%, Rankine cycle including the generator).

The trend in the $C_{\text {fuel }}$ of system 3 with changing $T_{\mathrm{el}}$ and $p_{\mathrm{el}}$ showed much lower values than system 2 . This is due to the dominant benefits of the significantly enhanced solar-to-thermal efficiency of a concentrated solar thermal system, leading to a smaller heliostat field area for heating, and compensating the cost drawback of the CSP sub-system.

\subsection{Performance and cost sensitivity of system 3}

\subsubsection{Effect of current density}

For system 3, the impact of the electrolyzer operational current density, $J_{\mathrm{el}}$, on $\eta_{\mathrm{STF}}$ and $C_{\text {fuel }}$, for changing $T_{\mathrm{el}}$ and $p_{\mathrm{el}}$, is shown in Fig. 5a and b. Generally, larger $J_{\mathrm{el}}$ caused a decrease in $\eta_{\mathrm{STF}}$ due to increased operating cell potential (Eqs. (12) and (14)), which in turn increased power demand. At a low temperature range (800-1100 K), $C_{\text {fuel }}$ first decreased to a minimum value with increasing $J_{\mathrm{el}}$, which resulted from the reduced electrolyzer area demand for a given plant size ( $400 \mathrm{~kg} \mathrm{H}_{2} /$ day), and then increased when further increasing $J_{\mathrm{el}}$, resulting from the dominant influence of ohmic losses. For example at $T_{\mathrm{el}}=800 \mathrm{~K}$, the $C_{\text {fuel }}$ decreased from
$\$ 10.35 / \mathrm{kg}$ to $\$ 9.85 / \mathrm{kg}$ when $J_{\mathrm{el}}$ increased from $1000 \mathrm{~A} / \mathrm{m}^{2}$ to $2000 \mathrm{~A} / \mathrm{m}^{2}$, while the other parameters were held at the reference values. However, $C_{\text {fuel }}$ increased from $\$ 9.85 / \mathrm{kg}$ to $\$ 10.56 / \mathrm{kg}$ as $J_{\mathrm{el}}$ further increased from $2000 \mathrm{~A} / \mathrm{m}^{2}$ to $3000 \mathrm{~A} / \mathrm{m}^{2}$ as a result of increasing ohmic overpotential. As $T_{\mathrm{el}}$ increased, the minimum $C_{\text {fuel }}$ moved to larger $J_{\mathrm{el}}$ due to the exponential reduction of ohmic overpotential (Eq. (14)) at elevated temperatures. The minimum $C_{\text {fuel }}$ was obtained at $J_{\mathrm{el}}>10,000 \mathrm{~A} / \mathrm{m}^{2}$ (the uper limit of $J_{\mathrm{el}}$ investigated in this study) when $T_{\mathrm{el}}>1100 \mathrm{~K}$. The decrease in $\eta_{\mathrm{STF}}$ with increasing $J_{\mathrm{el}}$ was affected by $T_{\mathrm{el}}$ and $p_{\mathrm{el}}$ : the magnitude of the drop in $\eta_{\mathrm{STF}}$ with increasing $J_{\mathrm{el}}$ decreased with increasing $T_{\mathrm{el}}$ (Fig. 5a) and increasing $p_{\mathrm{el}}$ (Fig. 5b). For example, the absolute reduction of $\eta_{\mathrm{STF}}$ was 5.38 percentage points at $800 \mathrm{~K}$, and 0.81 percentage points at $1200 \mathrm{~K}$, when $J_{\mathrm{el}}$ was increased from $1000 \mathrm{~A} / \mathrm{m}^{2}$ to $10000 \mathrm{~A} / \mathrm{m}^{2}$. The $\eta_{\mathrm{STF}}$ was relatively insensitive to changes in $J_{\mathrm{el}}$ at higher $p_{\mathrm{el}}$. For example, the absolute reduction in $\eta_{\mathrm{STF}}$ was 2.75 percentage points at $10 \mathrm{~atm}$, and 3.96 percentage points at $1 \mathrm{~atm}$.

Isothermal operation was assumed in the current study, which assumes that the electrolyzer and inlet and outlet gas temperatures are at a constant temperature. This requires additional heating or cooling equipment for the electrolyzer depending on the difference between operation voltage, $\left\langle V_{\mathrm{el}}\right\rangle$, and thermoneutral voltage, $V_{\mathrm{tn}}$. If $\left\langle V_{\mathrm{el}}\right\rangle>V_{\mathrm{tn}}$, the electrolyzer works at an exothermic voltage, requiring a cooling device to maintain the temperature. If $\left\langle V_{\mathrm{el}}\right\rangle<V_{\mathrm{tn}}$, additional heating is required. Operation at thermoneutral voltage simplifies the system design and avoids the need for additional heating or cooling components. The combinations of $T_{\mathrm{el}}, p_{\mathrm{el}}$, and $J_{\mathrm{el}}$ resulting in thermoneutural voltage operation are shown in Fig. 5c. Thermoneutral operation is achieved when simultaneously increasing $J_{\mathrm{el}}$ and $T_{\mathrm{el}}$ at $p_{\mathrm{el}}=10 \mathrm{~atm}$, suggesting that high efficiency and low cost can be achieved under thermoneutral electrolyzer conditions (Fig. 5a). For example: under thermoneutral operation, $\eta_{\mathrm{STF}}=9.95 \%$ and $C_{\text {fuel }}=\$ 6.29 / \mathrm{kg}$ for $T_{\mathrm{el}}=1000 \mathrm{~K}, p_{\mathrm{el}}=10 \mathrm{~atm}$, and $J_{\mathrm{el}}=4642 \mathrm{~A} / \mathrm{m}^{2}$, while for the same $T_{\mathrm{el}}$ and $p_{\mathrm{el}}$, either $(i)$ the maximal $\eta_{\mathrm{STF}}(11.4 \%)$ was achieved at $J_{\mathrm{el}}=1000 \mathrm{~A} / \mathrm{m}^{2}$, and at a potential lower than $V_{\mathrm{tn}}(0.258 \mathrm{~V}$ lower $)$, or (ii) the minimum $C_{\text {fuel }}(\$ 6.28 / \mathrm{kg})$ was achieved at $J_{\mathrm{el}}=10,000$ $\mathrm{A} / \mathrm{m}^{2}$, and at a potential slightly larger than $V_{\mathrm{tn}}(0.022 \mathrm{~V}$ higher $)$. For a fixed $T_{\mathrm{el}}$, a decrease in $p_{\mathrm{el}}$ resulted in larger $J_{\mathrm{el}}$ at thermoneutral conditions, resulting from the reduced Nernst potential, which in turn further reduced $C_{\text {fuel }}$. Additionally, the larger $J_{\mathrm{el}}$ reduces the electrolyzer cost, further reducing $C_{\text {fuel }}$.

\subsubsection{Effect of heat exchange effectiveness}

Since the electrolyzer working temperature is in the range of $800-1500 \mathrm{~K}$, large amounts of heat are required for heating the reactants and the sweep gas, leading to a significant influence of 

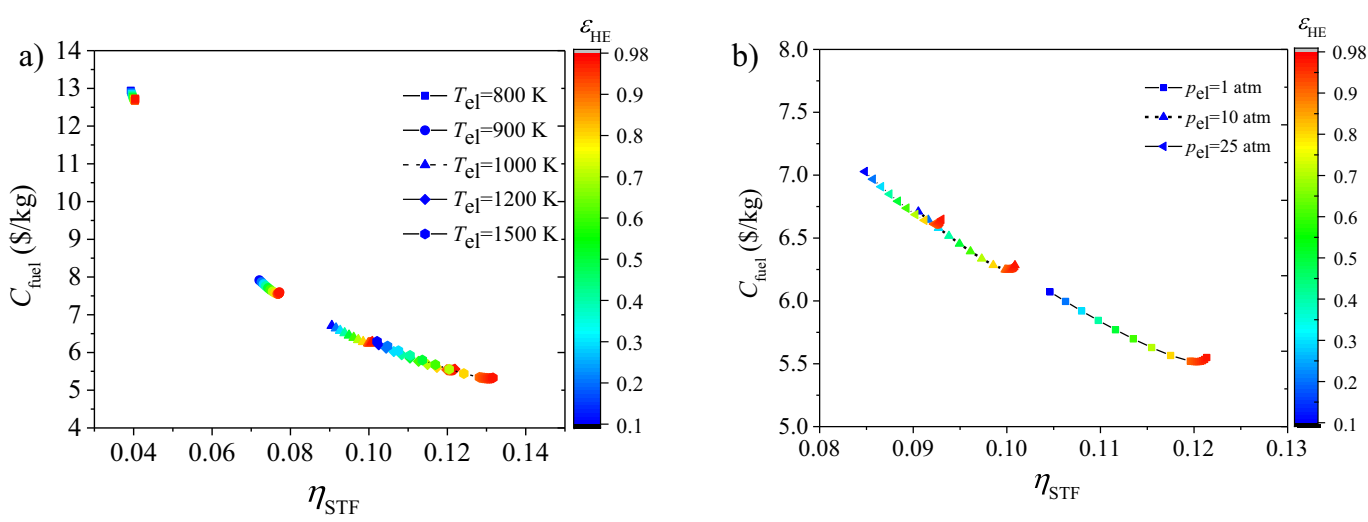

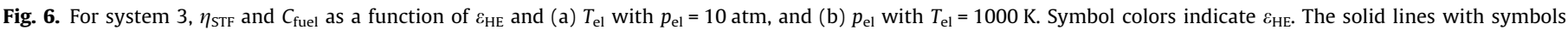
represent $T_{\mathrm{el}}$ for (a), and $p_{\mathrm{el}}$ for (b). Dashed lines are for the reference case with changing $\varepsilon_{\mathrm{HE}}$.
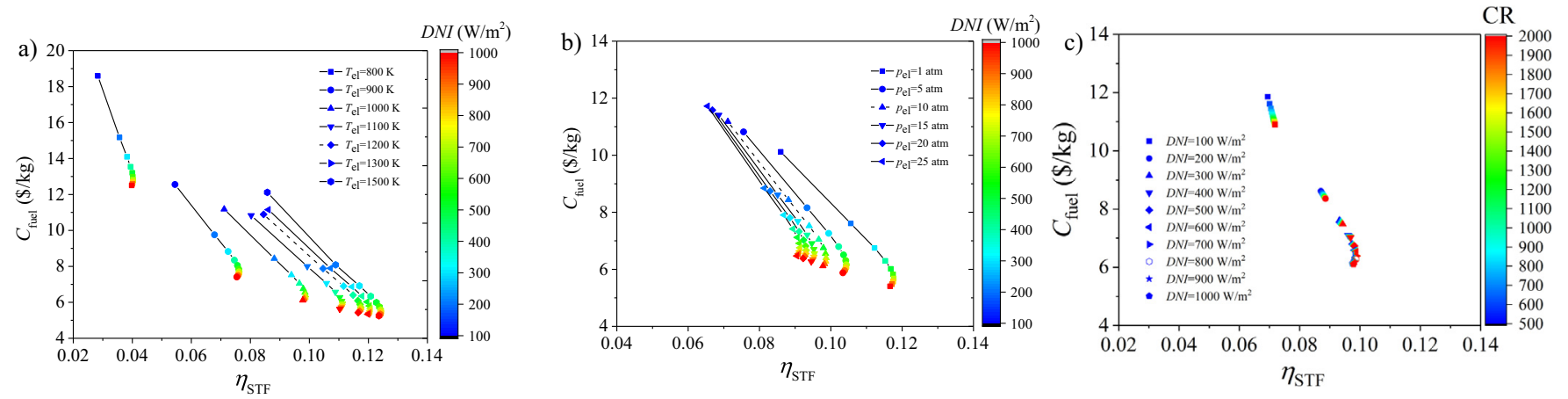

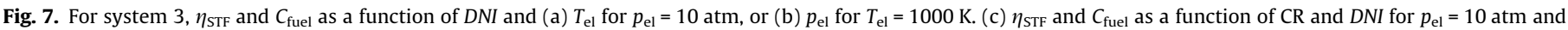

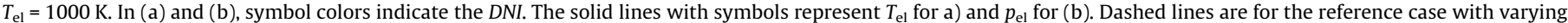
$D N I$. In (c), symbols represent varying CR, and hollow symbols are for reference cases with changing DNI.

heat exchange effectiveness on system efficiency. The cost of the heat exchanger is exponentially dependent on the heat exchanger area (Eq. (34)), which also depends on the heat transfer coefficient (depending on the phase of the streams). As depicted in Fig. $6, C_{\text {fuel }}$ first decreases with increasing $\varepsilon_{\mathrm{HE}}$ due to increasing system efficiency, and then increases due to the dominance of the heat exchanger costs. For the selected cases shown in Fig. 6, the minimal $C_{\text {fuel }}$ at $T_{\mathrm{el}}=800 \mathrm{~K}$ was obtained at $\varepsilon_{\mathrm{HE}}=0.9$, and $\varepsilon_{\mathrm{HE}}$ increased to 0.94 as $T_{\mathrm{el}}$ increased to $1200 \mathrm{~K}$. Increasing $\varepsilon_{\mathrm{HE}}$ beyond the minimum $C_{\text {fuel }}$ point led to a sharper increase in $C_{\text {fuel }}$ at lower $T_{\mathrm{el}}$. The $\eta_{\mathrm{STF}}$ always increased with increasing $\varepsilon_{\mathrm{HE}}$ due to increased heat recovery and, consequently, reduced requirement for energy input. Increasing $\varepsilon_{\mathrm{HE}}$ beyond the minimum $C_{\text {fuel }}$ point led to a less steep increase in $\eta_{\mathrm{STF}}$ at lower $T_{\mathrm{el}}$. This comes from the increased heat exchanger area required at elevated temperatures, which in turn exponentially increases the heat exchanger cost. Efficiency increased at higher temperatures due to reduced electrolyzer cell potential. The minimum $C_{\text {fuel }}$ at $T_{\mathrm{el}}=1000 \mathrm{~K}$ was obtained at a constant $\varepsilon_{\mathrm{HE}}=0.93$ for different $p_{\mathrm{el}}$ since the increase in the heat exchanger cost starts to dominate the cost reduction due to decreasing $A_{\text {heliostat. }}$

\subsubsection{Effect of solar irradiation}

The impact of direct normal irradiance, $D N I$, on $\eta_{\mathrm{STF}}$ and $C_{\text {fuel }}$ for system 3 under various $T_{\mathrm{el}}$ and $p_{\mathrm{el}}$ is shown in Fig. $7 \mathrm{a}$ and $\mathrm{b}$. Changes in DNI result from variation in location, and seasonal and daily changes. For the concentrated solar system, only the direct part of the solar irradiation can be utilized, while both the direct and diffuse parts can be harvested by the photovoltaic system. For comparison reasons, we considered both $\mathrm{DHI}$ and $\mathrm{DNI}$ in solar irradiation, assuming $D H I$ only depends on $D N I$, calculated with the equation introduced in Section 3.3. Generally, $\eta_{\text {STF }}$ increases and $C_{\text {fuel }}$ decreases with increasing DNI due to increasing solar receiver efficiency and PV system efficiency. The increasing temperature of the PV reduces the efficiency (Eqs. (22) to (24)), and this effect starts to be dominant at $D N I>700 \mathrm{~W} / \mathrm{m}^{2}$ at the reference condition. The optimal DNI in terms of $\eta_{\text {STF }}$ is always $700 \mathrm{~W} / \mathrm{m}^{2}$ for various $T_{\mathrm{el}}$ and $p_{\mathrm{el}}$ with other parameters at reference conditions. However, the increased DNI always leads to reduced solar field areas, which in turn leads to lower investment cost.

\subsubsection{Effect of concentration ratio}

The concentration ratio, $\mathrm{CR}$, is defined as the ratio between the solar power intensity at the cavity receiver aperture and the DNI. Variation in CR affects the aperture size of the receiver at a constant input power, resulting in changing the thermal performance of the cavity receiver. The ratio of cavity length to aperture radius was held constant at 3 , and the surface emissivity at 0.88 . For system 3, the effect of CR on $\eta_{\text {STF }}$ and $C_{\text {fuel }}$ for various $D N I$ is shown in Fig. 7c. We chose a range of CR between 500 and 2000, representing typical values for solar tower concentrating technologies.

For system 3 , the larger the CR, the larger the $\eta_{\mathrm{STF}}$ and the lower the $C_{\text {fuel }}$ at reference conditions for all DNI. The increase of $\eta_{\text {STF }}$ and decrease of $C_{\text {fuel }}$ is more pronounced at lower DNI. The increase of $\mathrm{CR}$, effectively reducing the aperture radius, leads to the decreased re-radiation losses. This effect was less pronounced at elevated $D N I$, which can be explained by the already reduced re-radiation losses for increasing DNI, diluting the effect of CR. This suggests 

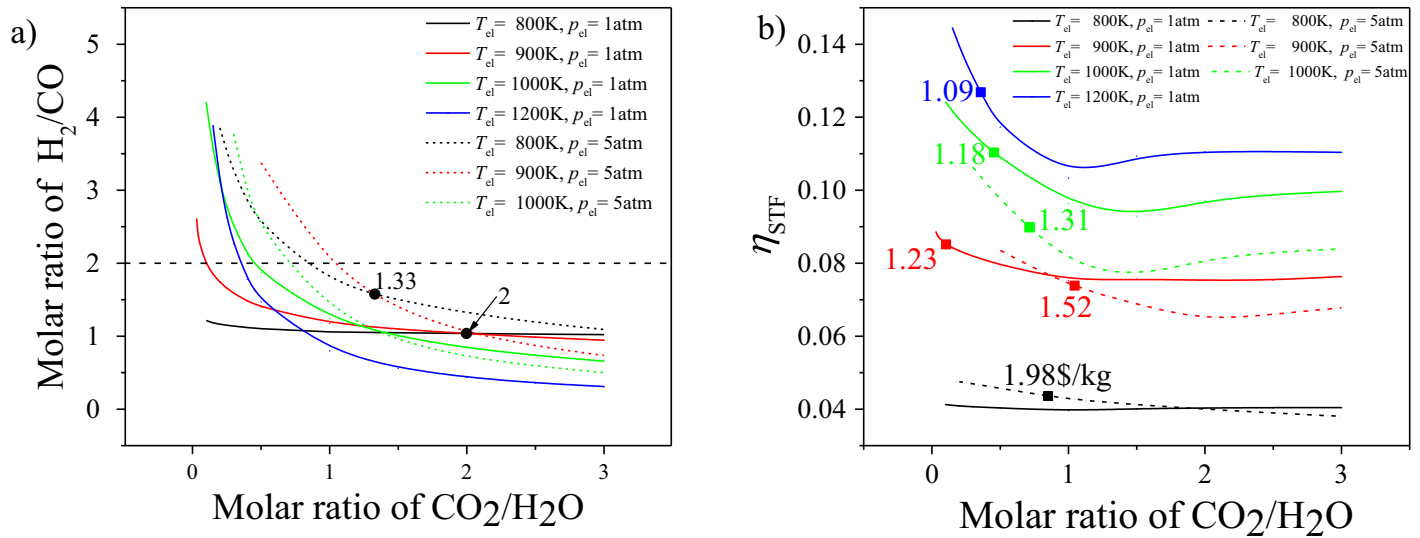

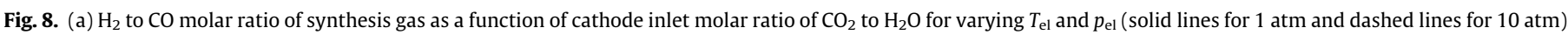

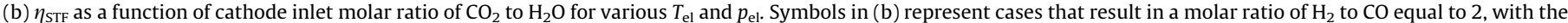
number indicating the corresponding fuel cost.

that CR is not the limiting factor for high $\eta_{\mathrm{STF}}$ and low $C_{\text {fuel }}$ when the DNI of the chosen location is larger than $300 \mathrm{~W} / \mathrm{m}^{2}$.

\subsubsection{Effect of water conversion extent}

For system 3 , the effect of water conversion extent, $W_{\text {ce }}$, on $\eta_{\text {STF }}$ and $C_{\text {fuel }}$ for varying $T_{\mathrm{el}}$ and $p_{\mathrm{el}}$ is shown in Fig. S6. The increase of $W_{\text {ce }}$ can lead to three contradictory effects: $(i)$ a reduced energy need for heating the water to the required operational temperature (i.e. the total fluid heating demand was $1974.1 \mathrm{~kW}$ at the reference conditions, and decreased to $514.9 \mathrm{~kW}$ for $W_{\text {ce }}=1$ ), (ii) mass transport limitations in the porous cathode increasing the Nernst potential (i.e. $0.954 \mathrm{~V}$ at the reference conditions, increased to $1.037 \mathrm{~V}$ for $W_{\text {ce }}=1$ ), which in turn leads to an increased electrolyzer electricity demand (i.e. total electricity demand for the electrolyzer was $1750 \mathrm{~kW}$ at the reference conditions, increased to $1861 \mathrm{~kW}$ for $W_{\mathrm{ce}}=1$ ), and (iii) reduced requirements for pumping of the fluid (i.e. total pumping power demand was $374.4 \mathrm{~kW}$ at the reference conditions, decreased to $74.9 \mathrm{~kW}$ for $\left.W_{\mathrm{ce}}=1\right)$. As shown in Fig. S6, the increase of $W_{\text {ce }}$ always benefits $\eta_{\text {STF }}$ and $C_{\text {fuel }}$, dominantly coming from the effects of reduced heating and pumping demands compared to the increased electricity demand of the electrolyzer (due to increasing Nernst potential). Generally, an increase in $W_{\text {ce }}$ leads to increasing $\eta_{\text {STF }}$ and decreasing $C_{\text {fuel }}$. However, lower $p_{\mathrm{el}}$ may result in mass transport limitations of the water in the cathode. For example at $p_{\mathrm{el}}=1 \mathrm{~atm}$, an increase of $W_{\text {ce }}$ above 0.85 reduced $\eta_{\text {STF }}$, which resulted primarily from the potential increase effects over the benefit of pumping and heating demand reduction. At a constant $W_{\text {cee }}$, a reduction in pressure reduces $C_{\text {fuel }}$ because of the reduced compression demand.

\subsection{Synthesis gas production in system 3}

In the context of synthesis gas production, the desired molar ratio of $\mathrm{H}_{2}$ and $\mathrm{CO}$ in synthesis gas varies according to the targeted liquid fuel. For example, a $\mathrm{H}_{2} / \mathrm{CO}$ ratio of $2: 1$ is required for the synthesis of methanol (O'Brien et al., 2009). In this study, we focused on a particular $\mathrm{H}_{2} / \mathrm{CO}$ production ratio, as an example, of 2 , and we investigated the effect of the working conditions on $\eta_{\text {STF }}$ and $C_{\text {fuel }}$, and the required cathode inlet gas composition at the reference conditions.

Fig. 8 reveals the impact of $T_{\mathrm{el}}, p_{\mathrm{el}}$, and cathode $\mathrm{CO}_{2} / \mathrm{H}_{2} \mathrm{O}$ inlet ratios on the product molar ratio of $\mathrm{H}_{2}$ to $\mathrm{CO}$. In general, the molar $\mathrm{H}_{2} / \mathrm{CO}$ ratio decreases with increasing $\mathrm{CO}_{2} / \mathrm{H}_{2} \mathrm{O}$ inlet molar ratio for a given $T_{\mathrm{el}}$. This is due to the reduction in $R_{\mathrm{WGSR}}$ (Fig. S4b) and the reduction in the concentration overpotential for $\mathrm{CO}_{2}$ splitting, lead- ing to increased current occupation for $\mathrm{CO}_{2}$ splitting and consequently to larger CO generation.

A higher $T_{\text {el }}$ resulted in lower $\mathrm{H}_{2} / \mathrm{CO}$ molar ratios for $\mathrm{CO}_{2} / \mathrm{H}_{2} \mathrm{O}$ inlet ratios larger than $2\left(p_{\mathrm{el}}=1 \mathrm{~atm}\right.$ with other parameters held at reference values), primarily due to the reverse WGSR. This reverse WGSR rate $\left(-R_{\mathrm{WGSR}}\right)$ was drastically increased with increasing $T_{\mathrm{el}}$, leading to decreases in $\mathrm{H}_{2} / \mathrm{CO}$ molar ratios. At smaller $\mathrm{CO}_{2} / \mathrm{H}_{2} \mathrm{O}$ molar inlet ratios $(<2)$, the resulting $\mathrm{H}_{2} / \mathrm{CO}$ molar ratios are mostly driven by the following effects: $(i)$ the decreasing difference between the equilibrium potential of $\mathrm{H}_{2} \mathrm{O}$ and $\mathrm{CO}_{2}$ with increasing $T_{\mathrm{el}}$ (Fig. S5), which leads to an increase in $\left.J_{\mathrm{CO}}, i i\right)$ the increase of $R_{\mathrm{WGSR}}$ with initial increase in $T_{\mathrm{el}}\left(T_{\mathrm{el}}<1009 \mathrm{~K}\right)$ and the sharp decrease of $R_{\mathrm{WGSR}}$ with further increase in $T_{\mathrm{el}}\left(T_{\mathrm{el}}>1009 \mathrm{~K}\right)$ (Fig. S4a), and (iii) the steeper decrease of $R_{\mathrm{WGSR}}$ with $\mathrm{CO}_{2} / \mathrm{H}_{2} \mathrm{O}$ molar inlet ratios at increasing $T_{\mathrm{el}}$ (Fig. S4b). The aforementioned factors lead to complex behavior of the $\mathrm{H}_{2} / \mathrm{CO}$ molar ratios. As $T_{\mathrm{el}}$ increases from $800 \mathrm{~K}$ to $1000 \mathrm{~K}$, the increase in $R_{\mathrm{WGSR}}$ dominated, which provoked an increase in the $\mathrm{H}_{2} / \mathrm{CO}$ molar ratio. Accordingly, the required $\mathrm{CO}_{2} / \mathrm{H}_{2} \mathrm{O}$ molar inlet ratios for a $\mathrm{H}_{2} / \mathrm{CO}$ molar ratio of 2 increased from 0.104 to 0.454 as $T_{\mathrm{el}}$ increased from $900 \mathrm{~K}$ to $1000 \mathrm{~K}$, both at $p_{\mathrm{el}}=1 \mathrm{~atm}$. As $T_{\mathrm{el}}$ further increased from $1000 \mathrm{~K}$ to $1200 \mathrm{~K}$, the equilibrium potential of $\mathrm{CO}_{2}$ became smaller than that of $\mathrm{H}_{2} \mathrm{O}$ (Fig. S5) leading to a significant increase in $J_{\text {CO. }}$. Furthermore, the sharp decrease in $R_{\text {WGSR }}$ at high $T_{\mathrm{el}}(>1009 \mathrm{~K})$ further reduced the production of $\mathrm{H}_{2}$. These two effects lead to a decrease in the $\mathrm{H}_{2} / \mathrm{CO}$ molar ratios. To maintain a $\mathrm{H}_{2} / \mathrm{CO}$ product ratio of 2 at $T_{\mathrm{el}}=1200 \mathrm{~K}$, a reduction in the $\mathrm{CO}_{2} / \mathrm{H}_{2} \mathrm{O}$ molar inlet ratio was required $\left(0.357\right.$ at $\left.T_{\mathrm{el}}=1200 \mathrm{~K}\right)$.

The influence of $p_{\mathrm{el}}$ on the product ratio $\left(\mathrm{H}_{2}\right.$ to $\left.\mathrm{CO}\right)$ is shown in Fig. 8a. To produce synthesis gas at a $\mathrm{H}_{2} / \mathrm{CO}$ product ratio of 2 , the required $\mathrm{CO}_{2} / \mathrm{H}_{2} \mathrm{O}$ molar inlet ratio must be increased, compared to the $p_{\mathrm{el}}=1 \mathrm{~atm}$ case, in order to counteract the increase of $R_{\mathrm{WGSR}}$ with increasing $p_{\mathrm{el}}$. For example, the corresponding $\mathrm{CO}_{2} / \mathrm{H}_{2} \mathrm{O}$ molar inlet ratio at $1000 \mathrm{~K}$ was 0.104 at $p_{\mathrm{el}}=1 \mathrm{~atm}$ and increased to 1.046 at $p_{\mathrm{el}}=5 \mathrm{~atm}$.

Fig. 8b shows $\eta_{\text {STF }}$ as a function of $\mathrm{CO}_{2} / \mathrm{H}_{2} \mathrm{O}$ molar inlet ratio for varying $T_{\mathrm{el}}$ and $p_{\mathrm{el}}$. Generally, working at lower $p_{\mathrm{el}}$ and higher $T_{\mathrm{el}}$ leads to higher $\eta_{\text {STF }}$. For cases with a $\mathrm{H}_{2} / \mathrm{CO}$ molar product ratio of 2 , high $\eta_{\mathrm{STF}}(12.7 \%)$ and low $C_{\text {fuel }}(\$ 1.09 / \mathrm{kg})$ were achieved at elevated $T_{\mathrm{el}}(1200 \mathrm{~K})$ and low $p_{\mathrm{el}}(1 \mathrm{~atm})$.

\section{Summary and conclusions}

A methodology for the techno-economic assessment of solardriven high-temperature electrolysis (HTE) of water and $\mathrm{CO}_{2}$ to 
hydrogen and $\mathrm{CO}$ was developed in order to compare the performance and cost of three different solar integration schemes at various working conditions. The three solar integration schemes incorporated concentrated solar technology (system 1), photovoltaic technology (system 2), and the combination thereof (system 3) for the production of power and heat needed in the process. The impact of operating temperature, pressure, current density, heat recovery effectiveness, direct normal irradiance, conversion extent, and concentration ratio was investigated and discussed. The model is developed for the qualitative technoeconomic performance evaluation for different solar integration schemes under various operation conditions.

System 1, utilizing only concentrated solar technology for the production of heat and electricity, is able to work at high efficiency, but exhibits large fuel costs resulting from the expensive concentrated solar heat and power technologies. System 2, utilizing only PV technology, allowed for the production of hydrogen at a reduced levelized cost of $\$ 8.02 / \mathrm{kg}$ at the reference condition. This resulted from the smaller costs of PV technologies compared to concentrated solar power (CSP) technologies. System 3 provides a superior and more competitive techno-economic performance compared to systems 1 and 2 individually. The predicted hydrogen price (especially for system 3 ) is competitive with other solar hydrogen and fuel processing technologies.

Higher operating temperature is always favorable for the solar-to-fuel efficiency in system 1 and 3. There exists an optimal electrolyzer operating temperature for system 2 (1300 K) which allows to achieve the highest solar-to-fuel efficiency. Further increase in temperature leads to larger heating demand, resulting in reduced efficiency. The system 2 shows higher fuel cost at high temperature ( $>1050 \mathrm{~K}$ at $10 \mathrm{~atm})$ and this transition temperature increases with increasing pressure. Working at ambient pressure shows the best performance in terms of efficiency and fuel price.

The system can be optimized by tuning the operational temperature and pressure in order to achieve a current density which results in minimized efficiency drop and maximized cost reduction. Operation at thermoneutral voltage is suggested to simplify the heat management of the electrolyzer and shows to be close to the cost and efficiency-optimum case for large temperatures and small pressures. Optimized temperature and current density combinations for the thermoneutral operation were predicted, resulting in high efficiency and low fuel cost.

A high heat exchanger effectiveness leads to higher efficiency due to increased heat recovery. However, large heat exchanger effectiveness requires a larger heat exchanger area, leading to exponentially increased heat exchanger cost. Consequently, an optimal effectiveness for minimized fuel price is observed (around $90 \%$ ). This optimal effectiveness value needs to be chosen for each system design and operating conditions.

Larger DNI results in lower fuel cost due to reduced needed solar field area in the concentrated solar system (the dominating cost of systems 1 and 3) and due to the reduced receiver heat losses owing to the decreased receiver aperture. For system 2, initially PV efficiency increases with increasing DNI. However, the solar-to-fuel efficiency was affected at high DNI $\left(>700 \mathrm{~W} / \mathrm{m}^{2}\right)$ due to the increased PV cell temperature, reducing solar-to-electricity efficiency. Consequently, plant location and local irradiation conditions need to be carefully considered for system 2 , while systems 1 and 3 should be built at locations with the largest possible DNI.

Generally, larger water conversion results in larger efficiency and lower fuel cost. However, at large conversion rates, mass transport limits increased the Nernst potential which, in turn, counteracts the benefit of the reduced heating and pumping energy. Consequently, water conversion needs to be carefully tailored to the system and operating conditions for optimal system technoeconomic performance.
In the context of synthesis gas production, the effects of temperature and pressure on fuel price and efficiency are similar to the hydrogen production cases. Due to the concurrent electrolysis and water-gas shift reactions, a smart combination of inlet $\mathrm{CO}_{2} / \mathrm{H}_{2} \mathrm{O}$ molar fraction, $T_{\mathrm{el}}$, and $p_{\mathrm{el}}$ is required to produce a syngas product with a desired molar ratio of $\mathrm{H}_{2}$ to $\mathrm{CO}$ (here illustrated with a $\mathrm{H}_{2} / \mathrm{CO}$ ratio of 2). Lower $p_{\mathrm{el}}$ and higher $T_{\mathrm{el}}$ favors high efficiency and low cost syngas production with a $\mathrm{H}_{2} / \mathrm{CO}$ ratio of 2 . The system proposed allows to flexibly adjust the product composition by adjusting the inlet reactants composition, or the operational temperature or pressure. Consequently, such a plant can be combined with a variety of downstream processes, which may require different product composition as an input.

In summary, this work provides a complete, detailed, and flexible simulation framework for the evaluation of the performance and cost of three conceptually different solar-driven hightemperature electrolysis systems, differentiated by the utilization of different solar technologies for solar integration (concentrated solar or photovoltaics). We quantify the sensitivity of the performance and cost metrics towards operational conditions (temperature, pressure, current density, heat exchanger effectiveness, irradiation, and concentration ratio) and provide guidance for operational conditions which maximize the efficiency and minimize the cost. Our assessment and comparison of these three competing solar integration approaches predicts that the hybrid system proposed in this paper exhibits an efficiency and cost advantage compared to the others and should be considered a promising scalable approach to large-scale solar fuel processing.

\section{Acknowledgments}

The research leading to these results has received funding from the European Union's Seventh Framework Programme (FP7/20072013) for the Fuel Cells and Hydrogen Joint Technology Initiative under grant agreement no. 621173 (project SOPHIA). We thank the Chinese Scholarship Council for partial financial support of the doctoral studies of Meng Lin.

\section{Appendix A. Supplementary material}

Supplementary data associated with this article can be found, in the online version, at http://dx.doi.org/10.1016/j.solener.2017.07. 077.

\section{References}

Abanades, A., Rubbia, C., Salmieri, D., 2013. Thermal cracking of methane into hydrogen for a $\mathrm{CO}_{2}$-free utilization of natural gas. Int. J. Hydrogen Energy 38, 8491-8496.

Aicart, J., Petitjean, M., Laurencin, J., Tallobre, L., Dessemond, L., 2015. Accurate predictions of $\mathrm{H}_{2} \mathrm{O}$ and $\mathrm{CO}_{2}$ co-electrolysis outlet compositions in operation. Int J. Hydrogen Energy 40, 3134-3148. http://dx.doi.org/10.1016/j. ijhydene.2015.01.031.

Aicart, J., Usseglio-Viretta, F., Laurencin, J., Petitjean, M., Delette, G., Dessemond, L. 2016. Operating maps of high temperature $\mathrm{H}_{2} \mathrm{O}$ electrolysis and $\mathrm{H}_{2} \mathrm{O}+\mathrm{CO}_{2}$ coelectrolysis in solid oxide cells. Int. J. Hydrogen Energy 41, 17233-17246. http:// dx.doi.org/10.1016/j.ijhydene.2016.07.269.

AlZahrani, A.A. Dincer, I. 2016. Design and analysis of a solar tower based integrated system using high temperature electrolyzer for hydrogen production. Int. J. Hydrogen Energy 1-15. http://dx.doi.org/10.1016/j. ijhydene.2015.12.103.

Balat, M., 2009. Prospects for worldwide biodiesel market development. Energy Sources Part B 4, 48-58.

Becker, W.L., Braun, R.J., Penev, M., Melaina, M., 2012. Production of FischerTropsch liquid fuels from high temperature solid oxide co-electrolysis units. Energy 47, 99-115. http://dx.doi.org/10.1016/j.energy.2012.08.047.

Bertei, a., Nicolella, C., 2015. Common inconsistencies in modeling gas transport in porous electrodes: the dusty-gas model and the Fick law. J. Power Sources 279 , 133-137. http://dx.doi.org/10.1016/j.jpowsour.2015.01.007.

Bizzarri, F., Bongiorno, M., Brambilla, A., Gruosso, G., 2013. Model of photovoltaic power plants for performance analysis and production. Forecast 4, 278-285. 
Cengel, Y.A., Boles, M.A., Kanoğlu, M., 2002. Thermodynamics: an Engineering Approach. McGraw-Hill, New York.

De Soto, W., Klein, S.A., Beckman, W.A., 2006. Improvement and validation of a model for photovoltaic array performance. Sol. Energy 80, 78-88. http://dx.doi. org/10.1016/j.solener.2005.06.010.

Duffie, J.A., Beckman, W.A., 2013. Solar Engineering of Thermal Processes. John Wiley \& Sons.

Fang, Q., Blum, L., Menzler, N.H., 2015. Performance and degradation of solid oxide electrolysis cells in stack. J. Electrochem. Soc. 162, F907-F912. http://dx.doi.org/ 10.1149/2.0941508jes.

Ferguson, J.R.R., Fiard, J.M.M., Herbin, R., 1996. Three-dimensional numerical simulation for various geometries of solid oxide fuel cells. J. Power Sources 58, 109-122. http://dx.doi.org/10.1016/0378-7753(95)02269-4.

Ferrero, D., Gamba, M., Lanzini, A., Santarelli, M., 2016. Power-to-Gas hydrogen: techno-economic assessment of processes towards a multi-purpose energy carrier. Energy Procedia. 101, 50-57. http://dx.doi.org/10.1016/ j.egypro.2016.11.007.

Fu, Q., Mabilat, C., Zahid, M., Brisse, A., Gautier, L., 2010. Syngas production via hightemperature steam $/ \mathrm{CO}_{2}$ co-electrolysis: an economic assessment. Energy Environ. Sci. 3, 1382. http://dx.doi.org/10.1039/c0ee00092b.

Gibson, T.L., Kelly, N.a., 2008. Optimization of solar powered hydrogen production using photovoltaic electrolysis devices. Int. J. Hydrogen Energy 33, 5931-5940. http://dx.doi.org/10.1016/j.ijhydene.2008.05.106.

Gielen, D., 2012. Renewable energy technologies: cost analysis series. Sol. Photovolt. 1,52 .

Gilman, P., Dobos, A., 2012. System Advisor Model, SAM 2011.12. 2: General Description. National Renewable Energy Laboratory (NREL), Golden CO.

Graves, C., Ebbesen, S.D., Mogensen, M., Lackner, K.S., 2011. Sustainable hydrocarbon fuels by recycling $\mathrm{CO}_{2}$ and $\mathrm{H}_{2} \mathrm{O}$ with renewable or nuclear energy. Renew. Sustain. Energy Rev. 15, 1-23. http://dx.doi.org/10.1016/j. rser.2010.07.014.

Haberman, B.A., Young, J.B., 2004. Three-dimensional simulation of chemically reacting gas flows in the porous support structure of an integrated-planar solid oxide fuel cell. Int. J. Heat Mass Transf. 47, 3617-3629. http://dx.doi.org/ 10.1016/j.ijheatmasstransfer.2004.04.010.

Holladay, J.D., Hu, J., King, D.L., Wang, Y., 2009. An overview of hydrogen production technologies. Catal. Today 139, 244-260. http://dx.doi.org/10.1016/ j.cattod.2008.08.039.

Houaijia, A., Roeb, M., Monnerie, N., Sattler, C., 2015. Solar power tower as heat and electricity source for a solid oxide electrolyzer: a case study. Int. J. Energy Res.

Howell, J.R., Siegel, R., Menguc, M.P., 2010. Thermal Radiation Heat Transfer. CRC Press.

Kistler, B.L., 1986. A User's Manual for DELSOL3: A Computer Code for Calculating the Optical Performance and Optimal System Design for Solar Thermal Central Receiver Plants. Sandia National Labs, Livermore, CA (USA).

Knibbe, R., Traulsen, M.L., Hauch, A., Ebbesen, S.D., Mogensen, M., 2010. Solid oxide electrolysis cells: degradation at high current densities. J. Electrochem. Soc. 157, B1209-B1217. http://dx.doi.org/10.1149/1.3447752.

Koh, J., Yoon, D., Oh, C.H., 2010. Simple electrolyzer model development for hightemperature electrolysis system analysis using solid oxide electrolysis cell. J. Nucl. Sci. Technol. 47, 599-607. http://dx.doi.org/10.1080/ 18811248.2010.9720957.

Koumi Ngoh, S., Ayina Ohandja, L.M., Kemajou, A., Monkam, L., 2014. Design and simulation of hybrid solar high-temperature hydrogen production system using both solar photovoltaic and thermal energy. Sustain. Energy Technol. Assessm. 7, 279-293. http://dx.doi.org/10.1016/j.seta.2014.05.002.

Laguna-Bercero, M.A., 2012. Recent advances in high temperature electrolysis using solid oxide fuel cells: a review. J. Power Sources. http://dx.doi.org/10.1016/j. jpowsour.2011.12.019.

Lienhard, J.H., 2013. A Heat Transfer Textbook. Courier Corporation.

Meier, A., Gremaud, N., Steinfeld, A., 2005. Economic evaluation of the industrial solar production of lime. Energy Convers. Manage. 46, 905-926.

Menon, V., Fu, Q., Janardhanan, V.M., Deutschmann, O., 2015. A model-based understanding of solid-oxide electrolysis cells (SOECs) for syngas production by $\mathrm{H}_{2} \mathrm{O} / \mathrm{CO}_{2}$ co-electrolysis. J. Power Sources 274, 768-781. http://dx.doi.org/ 10.1016/j.jpowsour.2014.09.158.

Milobar, D.G., Hartvigsen, J.J., Elangovan, S., 2015. A techno-economic model of a solid oxide electrolysis system. Faraday Discuss. 182, 329-339. http://dx.doi. org/10.1039/C5FD00015G.

Momma, A., Kato, T., Kaga, Y., Nagata, S., 1997. Polarization behavior of high temperature solid oxide electrolysis cells (SOEC). J. Ceram. Soc. Jpn. 105, 369373.

Myers, D.B., Ariff, G.D., James, B.D., Lettow, J.S., Thomas, C.E., Kuhn, R.C., 2002. Cost and performance comparison of stationary hydrogen fueling appliances. Hydrog. Progr. Off.
Neises, T., Wagner, M.J., 2012. Simulation of direct steam power tower concentrated solar plant. In: ASME 2012 6th Int. Conf. Energy Sustain. Parts A B, pp. 499-507. http://dx.doi.org/10.1115/ES2012-91364.

Ni, M., 2012a. An electrochemical model for syngas production by co-electrolysis of $\mathrm{H}_{2} \mathrm{O}$ and $\mathrm{CO}_{2}$. J. Power Sources 202, 209-216. http://dx.doi.org/10.1016/j. jpowsour.2011.11.080.

Ni, M., 2012b. 2D thermal modeling of a solid oxide electrolyzer cell (SOEC) for syngas production by $\mathrm{H}_{2} \mathrm{O} / \mathrm{CO}_{2}$ co-electrolysis. Int. J. Hydrogen Energy 37 6389-6399. http://dx.doi.org/10.1016/j.ijhydene.2012.01.072.

Ni, M., Leung, M.K.H., Leung, D.Y.C., 2007. Parametric study of solid oxide steam electrolyzer for hydrogen production. Int. J. Hydrogen Energy 32, 2305-2313. http://dx.doi.org/10.1016/j.ijhydene.2007.03.001.

O’Brien, J.E., McKellar, M.G., Stoots, C.M., Herring, J.S., Hawkes, G.L., 2009. Parametric study of large-scale production of syngas via high-temperature coelectrolysis. Int. J. Hydrogen Energy 34, 4216-4226. http://dx.doi.org/10.1016/j. ijhydene.2008.12.021.

Padin, J., 2000. Hybrid solar high-temperature hydrogen production system. Int. J. Hydrogen Energy 25, 295-317. http://dx.doi.org/10.1016/S0360-3199(99) 00028-2.

Ridler, D.E., Twigg, M.V., 1989. Steam Reforming, Catalyst Handbook. Wolfe Publishing Ltd, Cleveland, UK.

Rivera-Tinoco, R., Mansilla, C., Bouallou, C., 2010. Competitiveness of hydrogen production by high temperature electrolysis: impact of the heat source and identification of key parameters to achieve low production costs. Energy Convers. Manage. 51, 2623-2634. http://dx.doi.org/10.1016/j. enconman 2010.05 .028

Sağol, B.E., Seidel, U., Szabó, N., Schwarzburg, K., Hannappel, T., 2007. Basic concepts and interfacial aspects of high-efficiency III-V multijunction solar cells. Chim. Int. J. Chem. 61, 775-779.

Salzano, F., 1985. Water vapor electrolysis at high temperature: systems considerations and benefits. Int. J. Hydrogen Energy 10, 801-809. http://dx. doi.org/10.1016/0360-3199(85)90168-5.

Sanz-Bermejo, J., Gallardo-Natividad, V., Gonzalez-Aguilar, J., Romero, M., 2014a Comparative system performance analysis of direct steam generation central receiver solar thermal power plants in megawatt range. J. Sol. Energy Eng. 136, 11028. http://dx.doi.org/10.1115/1.4026279.

Sanz-Bermejo, J., Muñoz-Antón, J., Gonzalez-Aguilar, J., Romero, M., 2014b. Optima integration of a solid-oxide electrolyser cell into a direct steam generation solar tower plant for zero-emission hydrogen production. Appl. Energy 131, 238247. http://dx.doi.org/10.1016/j.apenergy.2014.06.028.

Sapountzi, F.M., Gracia, J.M., Fredriksson, H.O., Niemantsverdriet, J.H., 2017. Electrocatalysts for the generation of hydrogen, oxygen and synthesis gas. Prog. Energy Combust. Sci. 58, 1-35. http://dx.doi.org/10.1016/j. pecs.2016.09.001.

Saur, G., 2008. Wind-to-Hydrogen Project: Electrolyzer Capital Cost Study. Citeseer.

Shampine, L.F., Kierzenka, J., Reichelt, M.W., 2000. Solving boundary value problems for ordinary differential equations in MATLAB with bvp4c. Tutor. Notes, $437-$ 448.

Shaner, M.R., Atwater, H.A., Lewis, N.S., McFarland, E.W., 2016. A comparative technoeconomic analysis of renewable hydrogen production using solar energy. Energy Environ. Sci. 9, 2354-2371. http://dx.doi.org/10.1039/C5EE02573G.

Shi, Y., Luo, Y., Li, W., Ni, M., Cai, N., 2015. High temperature electrolysis for hydrogen or syngas production from nuclear or renewable energy. Handb. Clean Energy Syst.

Singer, C., Buck, R., Pitz-Paal, R., Müller-Steinhagen, H., 2010. Assessment of solar power tower driven ultrasupercritical steam cycles applying tubular centra receivers with varied heat transfer media. J. Sol. Energy Eng. 132, 41010. http:// dx.doi.org/10.1115/1.4002137.

Stoots, C.M., O'Brien, J.E., Herring, J.S., Hartvigsen, J.J., 2009. Syngas production via high-temperature coelectrolysis of steam and carbon dioxide. J. Fuel Cell Sci. Technol. 6, 11014. http://dx.doi.org/10.1115/1.2971061.

Vural, Y., Ma, L., Ingham, D.B., Pourkashanian, M., 2010. Comparison of the multicomponent mass transfer models for the prediction of the concentration overpotential for solid oxide fuel cell anodes. J. Power Sources 195, 4893-4904. http://dx.doi.org/10.1016/j.jpowsour.2010.01.033.

Wagner, M.J., 2008. Simulation and Predictive Performance Modeling of Utilityscale Central Receiver System Power Plants. University of Wisconsin-Madison.

Xu, G., Liang, F., Yang, Y., Hu, Y., Zhang, K., Liu, W., 2014. An improved $\mathrm{CO}_{2}$ separation and purification system based on cryogenic separation and distillation theory. Energies 7, 3484-3502. http://dx.doi.org/10.3390/ en7053484.

Zhan, Z., Kobsiriphat, W., Wilson, J.R., Pillai, M., Kim, I., Barnett, S.A., 2009. Syngas production by coelectrolysis of $\mathrm{CO}_{2} / \mathrm{H}_{2} \mathrm{O}$ : the basis for a renewable energy cycle. Energy Fuels 23, 3089-3096. http://dx.doi.org/10.1021/ef900111f. 